Review

\title{
Formulations of Curcumin Nanoparticles for Brain Diseases
}

\author{
María L. Del Prado-Audelo ${ }^{1}$, Isaac H. Caballero-Florán 2,3, Jorge A. Meza-Toledo 3,4, \\ Néstor Mendoza-Muñoz ${ }^{5} \mathbb{D}$, Maykel González-Torres ${ }^{6,7} \mathbb{D}$, Benjamín Florán ${ }^{2} \mathbb{D}$, \\ Hernán Cortés ${ }^{8, *(1)}$ and Gerardo Leyva-Gómez ${ }^{3, *}$
}

1 Laboratorio de Posgrado en Tecnología Farmacéutica, FES-Cuautitlán, Universidad Nacional Autónoma de México, Cuautitlán Izcalli 54740, Mexico; ml.delprado@iim.unam.mx

2 Departamento de Fisiología, Biofísica \& Neurociencias, Centro de Investigación y de Estudios Avanzados del Instituto Politécnico Nacional, Ciudad de México 07360, Mexico; hiram.qfohead@gmail.com (I.H.C.-F.); bfloran@fisio.cinvestav.mx (B.F.)

3 Departamento de Farmacia, Facultad de Química, Universidad Nacional Autónoma de México, Ciudad Universitaria, Circuito Exterior S/N, Del. Coyoacán, C.P. Ciudad de México 04510, Mexico; jamtoledo90@outlook.com

4 Escuela de Ciencias de la Salud, Universidad del Valle de México, Campus Coyoacán, Ciudad de México, 04910, Mexico

5 Facultad de Ciencias Químicas, Universidad de Colima, C.P. Colima 28400, México; nmendoza0@ucol.cmx

6 CONACyT-Laboratorio de Biotecnología, Instituto Nacional de Rehabilitación Luis Guillermo Ibarra Ibarra, Ciudad de México 14389, Mexico; mikegcu@gmail.com

7 Instituto Tecnológico y de Estudios Superiores de Monterrey, Campus Ciudad de México 14380, Mexico

8 Laboratorio de Medicina Genómica, Departamento de Genética, Instituto Nacional de Rehabilitación Luis Guillermo Ibarra Ibarra, Ciudad de México 14389, Mexico

* Correspondence: hcortes@inr.gob.mx or hcortes_c@hotmail.com (H.C.); gerardoleyva@hotmail.com (G.L.-G.); Tel.: +52-55-59991000 (ext. 14710) (H.C.); +52-55-56223899 (ext. 44408) (G.L.-G.)

Received: 14 December 2018; Accepted: 1 February 2019; Published: 8 February 2019

\begin{abstract}
Curcumin is a polyphenol that is obtained from Curcuma longa and used in various areas, such as food and textiles. Curcumin has important anti-inflammatory and antioxidant properties that allow it to be applied as treatment for several emerging pathologies. Remarkably, there are an elevated number of publications deriving from the terms "curcumin" and "curcumin brain diseases", which highlights the increasing impact of this polyphenol and the high number of study groups investigating their therapeutic actions. However, its lack of solubility in aqueous media, as well as its poor bioavailability in biological systems, represent limiting factors for its successful application. In this review article, the analysis of its chemical composition and the pivotal mechanisms for brain applications are addressed in a global manner. Furthermore, we emphasize the use of nanoparticles with curcumin and the benefits that have been reached as an example of the extensive advances in this area of health.
\end{abstract}

Keywords: curcumin; nanoparticles; inflammation; protein aggregation; brain diseases; Alzheimer's disease; Parkinson's disease

\section{Introduction}

Curcumin is an active natural polyphenol component of Curcuma longa. Due to its chemical structure, this molecule could be applied in several different fields, such as food, textile, and the pharmaceutical industry. It has been shown that curcumin possess anti-inflammatory and antioxidant properties [1,2]. It also presents a spread spectrum of molecular targets such as transcription factors 
and their receptors, growth factors, cytokines, genes, and adhesion molecules. For example, curcumin could inhibit the cell signaling pathway of nuclear factor kappa B (NF-kB), which is an important cellular target of cancer cells [3-5]. Additionally, the blockade of NF-kB triggers the reduction in the expression of different NF-kB-regulated products, such as tumor necrosis factor alpha (TNF- $\alpha$ ), interleukin 8 (IL-8), and cyclooxygenase 2 (COX-2), which play key roles in the inflammation process [6]. Furthermore, it has been recently demonstrated that curcumin may inhibit protein aggregation, such as amyloid- $\beta(\mathrm{A} \beta)$ protein, which is related to several neurological pathologies, such as Alzheimer's disease (AD) [7].

For these reasons, in recent years, there has been an increasing interest in curcumin-based treatments as managements for many disorders, such as brain diseases. However, its poor bioavailability, low solubility in aqueous media, instability in body fluids, and elevated degradation rate have limited the therapeutic applications of this drug. Different strategies, such as the use of nanotechnology, have emerged to tackle these problems. In general, nanoparticles-based drug delivery systems present important advantages, such as a long lifetime circulation, ability to improve the drug's aqueous solubility as well the bioavailability, and the capacity to overcome physiological barriers [8-10].

Many authors have demonstrated that curcumin-loaded nanoparticles comprise a very effective and attractive treatment for several diseases. Therefore, the main objective of this work is to present an extensive review of the properties of curcumin, the nanotechnology-based curcumin delivery systems, and its potential application for the treatment of brain diseases, particularly AD, Parkinson's disease (PD), and cancer.

\section{Curcumin Chemical Information}

Chemically, curcumin is a naturally polyphenol denominated (1E,6E)-1,7-bis(4-hydroxy-3methoxyphenyl)-1,6-heptadiene-3,5-dione) (Figure 1), which is isolated from the rhizomes of C. longa . From a structural point of view, there are three chemical entities in the molecule: two aromatic ring systems containing o-methoxy phenolic groups linked by a seven-carbon spacer consisting of an $\alpha, \beta$-unsaturated $\beta$-diketone moiety [11]. Therefore, the diketo group exhibits keto-enol tautomerism, meaning that curcumin can exist in equilibrium between the keto and the enol tautomer. However, nuclear magnetic resonance (NMR) studies carried out on a variety of solvents concluded that the enol form of curcumin is essentially the only form of this molecule in solution [12]. The relevance of the tautomerism was explored by Yanagizawa et al. [13]; these authors suggested that curcumin and its analogues exist predominantly in the enol form during binding to A $\beta$ fibrils/aggregates, in turn suggesting that the enolization of curcumin derivatives is crucial for binding to A $\beta$ aggregates in the treatment of AD. In this respect, some physicochemical properties are described below.<smiles>COc1cc(/C=C/C(=O)/C=C/c2ccc(/C=C/C(=O)CC(=O)/C=C/c3ccc(O)c(OC)c3)cc2OC)ccc1O</smiles>

Figure 1. Chemical structure of curcumin and keto-enol tautomerism.

\subsection{Thermal Analysis of Curcumin}

Thermogravimetric analysis is a common complementary tool to describe this molecule. Therefore, we performed an evaluation of the thermal degradation of curcumin at a heating rate of $10{ }^{\circ} \mathrm{C} / \mathrm{min}$ and under a nitrogen atmosphere. As can be observed in Figure 2a, the initial temperature of the mass loss is approximately $193{ }^{\circ} \mathrm{C}$. This behavior results in the decomposition of the turmeric powder; below this temperature, weight loss in the curcumin follows a gradual decrease related to the loss of moisture. In a complementary way, a differential scanning calorimetry thermogram (Figure 2b) 
showed a melting temperature for curcumin of $174.05^{\circ} \mathrm{C}$, which is in agreement with data reported previously [14].

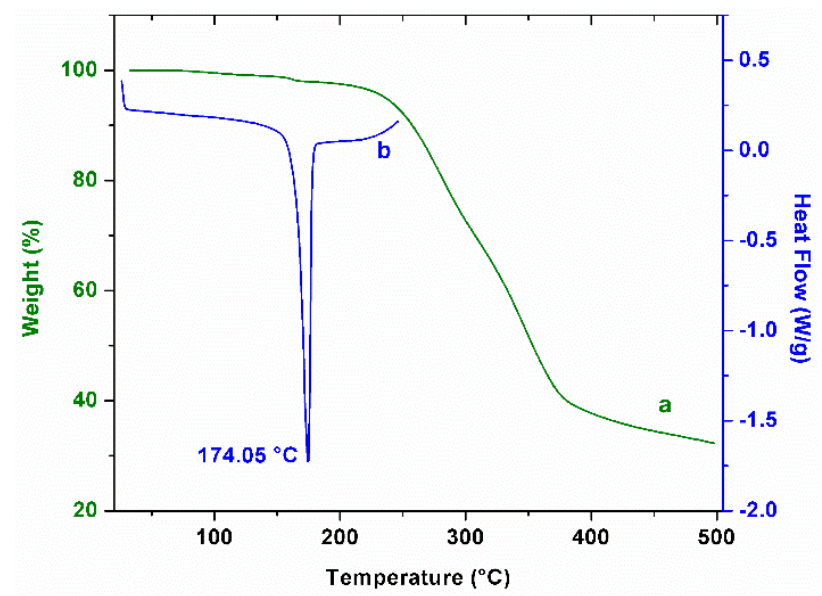

Figure 2. Thermal analysis of curcumin. Thermogravimetric analysis ((a), green line) and differential scanning calorimetry ((b), blue line). Melting point of curcumin is indicated at $174.05{ }^{\circ} \mathrm{C}$.

\subsection{Ultraviolet-Visible Spectrophotometric Analysis of Curcumin}

The chemical reactivity and solubility of curcumin depends on the medium $\mathrm{pH}$ in which it is dissolved; that is, under acidic conditions, curcumin exhibits moderate solubility, and the solution maintains a yellow color (Figure 3A), whereas at a neutral $\mathrm{pH}$, curcumin is not fully soluble, as can be observed in Figure 3B. On the other hand, within the basic $\mathrm{pH}$ range, curcumin is more water-soluble than in the neutral form, and the color of the solution changes to red (Figure 3C). The color change under alkaline conditions could be an effect deriving from the deprotonation. It is known that the photophysical and photochemical properties of curcumin are related to the solvents polarity because of the keto-enol structure of curcumin that involves intramolecular proton transfer [15]. Kharat M. et al. [16] mentioned the formation of condensation yellow products (such as feruloymethane) as a potential reason for this color increment under an alkaline environment.

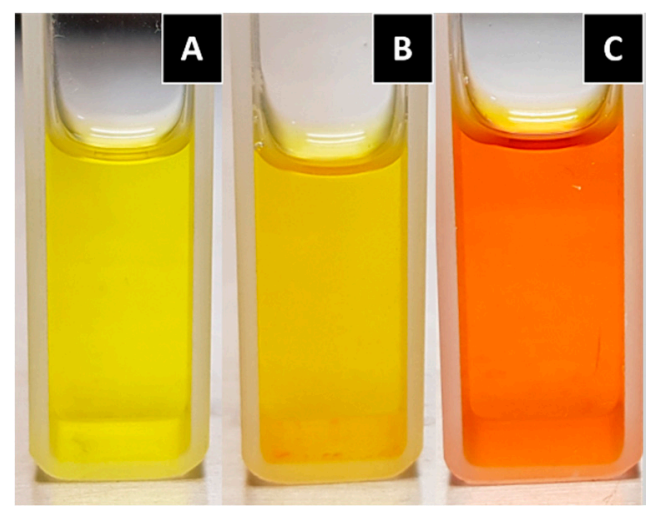

Figure 3. Curcumin dissolved in different mediums. (A) Curcumin in an acidic solution (pH 3.5); and (B) curcumin in a neutral solution ( $\mathrm{pH} 7.4)$; both with the addition of $1 \%$ Tween 80 in order to increase solubility. (C) Curcumin in a basic solution ( $\mathrm{pH} 12)$.

In order to corroborate the solubility of curcumin, we tested the drug incorporated in solvents with different $\mathrm{pH}$ levels (maintaining a concentration of eight $\mathrm{mg} / \mathrm{mL}$ ), through ultraviolet (UV)-vis spectrophotometry. Figure 4 depicts that at a neutral $\mathrm{pH}$ (lines a and $\mathrm{b}$ ), the maximum absorption peak of curcumin was found at $420 \mathrm{~nm}$, which is in agreement with the literature [17], while the maximum absorption in alkaline $\mathrm{pH}$ was found at $470 \mathrm{~nm}$ (Figure 4 , line c). This result is in agreement 
with the reported by Priyadarsini [11], who reported that the maximum absorption peak of the fully deprotonated curcumin is found at $467 \mathrm{~nm}$ under alkaline conditions (>pH 10).

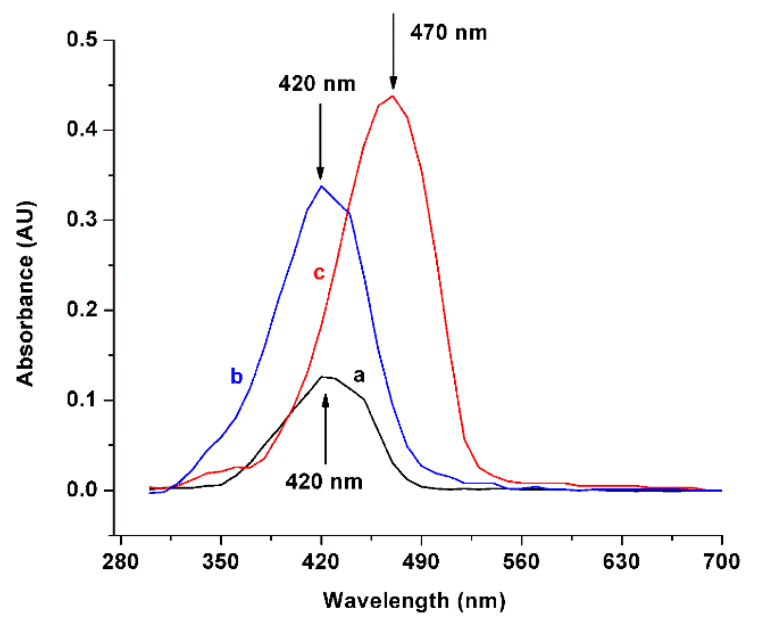

Figure 4. Ultraviolet-Visible spectrophotometric scanning of curcumin. (a) Absorption in methanol, maximum peak of absorption found at $420 \mathrm{~nm}$; (b) Absorption in neutral medium, maximum peak of absorption found at $420 \mathrm{~nm}$; and (c) Absorption in basic medium, maximum peak of absorption found at $470 \mathrm{~nm}$.

\subsection{Fourier Transform Infrared Spectroscopy of Curcumin}

Infrared spectroscopy is commonly employed to study the molecules' chemical structure; a curcumin spectrum is shown in Figure 5. As depicted, the characteristic band of the $\mathrm{O}-\mathrm{H}$ bond stretching appears at $3506 \mathrm{~cm}^{-1}$. The infrared (IR) band at $2915 \mathrm{~cm}^{-1}$ and its doublet at $2847 \mathrm{~cm}^{-1}$ are due to the asymmetric and symmetric stretching vibrations of the $\mathrm{C}-\mathrm{H}_{2}$ group. For $\mathrm{C}-\mathrm{C}$ stretching, a peak at $1624 \mathrm{~cm}^{-1}$ is found. The $\mathrm{C}=\mathrm{O}$ stretching vibration of the carboxylic groups (methyl esters and triglycerides) can be attributed to the strong band at $1510 \mathrm{~cm}^{-1}$ [18]. In plane $\mathrm{C}-\mathrm{OH}$ bending vibration can be assigned to the IR bands at $1375 \mathrm{~cm}^{-1}$. Curcumin shows a peak at around $1270 \mathrm{~cm}^{-1}$, which corresponds to the $\mathrm{C}-\mathrm{O}$ stretching frequency of the ether group in curcumin. The peaks at $729 \mathrm{~cm}^{-1}, 806 \mathrm{~cm}^{-1}$, and $955 \mathrm{~cm}^{-1}$ indicate the bending vibrations of the $-\mathrm{CH}$ bond of the alkene group [19].

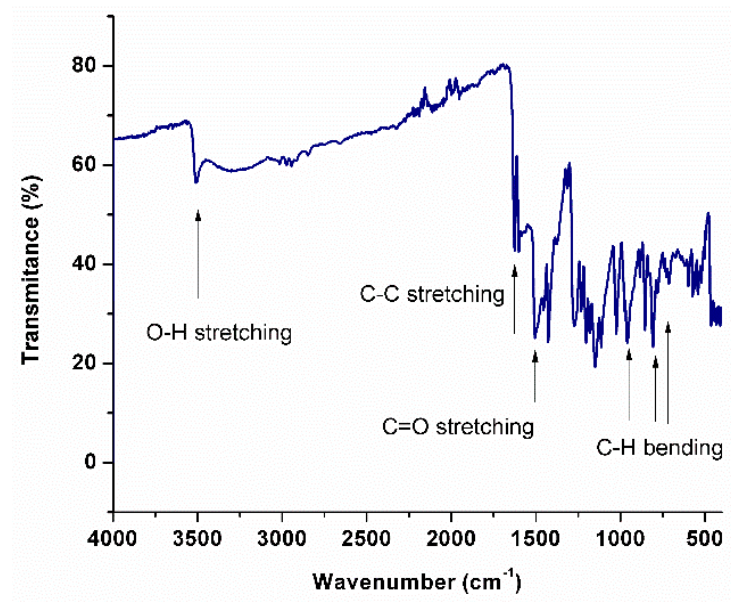

Figure 5. Fourier transform infrared spectroscopy of curcumin. Characteristic bands of the molecule are indicated with arrows. 


\subsection{Solubility}

Curcumin has poor solubility in water (an estimated of $3.21 \mathrm{mg} / \mathrm{L}$ at $25^{\circ} \mathrm{C}$ ); however, it is soluble in ethanol, dimethyl sulfoxide (DMSO), methanol, acetonitrile, chloroform, and ethyl acetate [11,20]. The theoretical Hansen solubility parameters (HSP), which were calculated on the basis of the group contribution method, are $\delta_{\mathrm{d}}=17.46, \delta_{\mathrm{p}}=3.66, \delta_{\mathrm{h}}=13.84$, and $\delta_{\text {total }}=22.46$ for the enol form of curcumin [21]. The first $\mathrm{pKa}_{1}=7.5-8.5$ corresponds to the deprotonation of the enolic proton group, while $\mathrm{pKa}_{2}=8.5-10.4$ and $\mathrm{pKa}_{3}=9.5-10.7$ are for the phenolic protons, indistinctly [11]. The log octanol-water partition coefficient (log Kow) is 3.29 (estimated), conferring hydrophobic characteristics on the molecule [20].

Curcumin is unstable in aqueous and alcoholic solution, and it is more stable in acidic $\mathrm{pH}(1.2-6)$ than in alkaline $\mathrm{pH}$ (Figure 3); the degradation products found under hydrolytic conditions are: trans-6-(4'-hydroxy-3'-methoxyphenyl)-2,4-dioxo-5-hexenal, ferulic acid, ferulic aldehyde, feruloylmethane, and vanillin $[22,23]$. However, new evidence suggests that the major degradation product is bicyclopentadione, which is the result of the autoxidation of curcumin [24], and is formed by the oxygenation and double cyclization of the heptadienedione chain connecting the two methoxyphenol rings of curcumin [25]. Curcumin is also sensitive to light. It has been shown to decompose when it is exposed to UV/visible light, both in solution and in the solid state [26].

\section{Biological Activity}

Curcumin has a broad spectrum of biological activities. For example, it has been reported as possessing antioxidant, anti-AD, anticarcinogenic, antimutagenic, and anti-inflammatory properties (Figure 6).

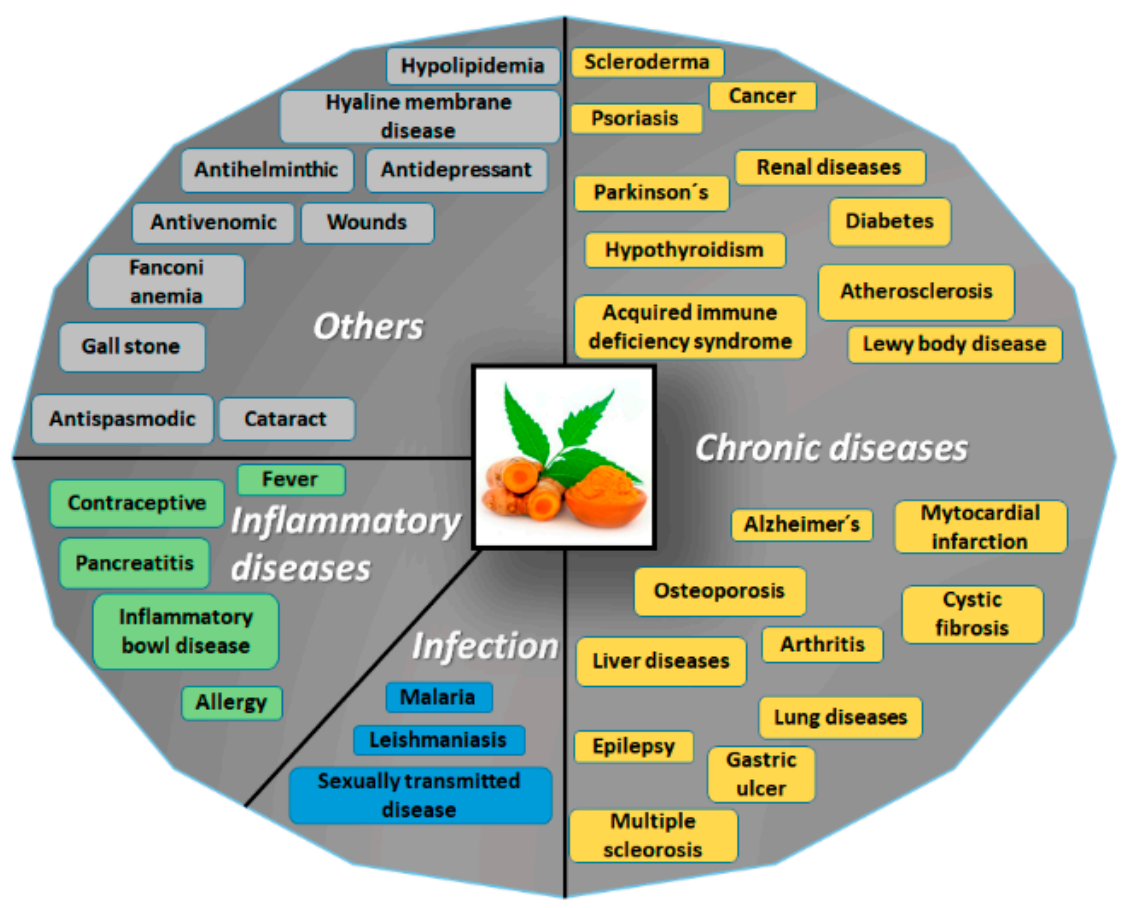

Figure 6. Potential applications of curcumin. Due to the structure of curcumin, this molecule could be applied as treatment for a wide range of disorders, such as chronic diseases, inflammatory disorders, infections of diverse etiology, and other conditions. Adapted with permission from [26]. 2007, Springer Nature.

With respect to antioxidant activity, evidence has shown that curcumin can directly scavenge several free radicals as the result of its two phenolic sites. Likewise, curcumin has been effective against the generation of reactive oxygen species (ROS) and reactive nitrogen species (RNS) in the 
cellular environment. Curcumin also reduces low-density lipoprotein (LDL), and inhibits the oxidation of proteins and DNA. At the enzymatic level, curcumin inhibits lipoxygenase/cyclooxygenase and xanthine dehydrogenase/oxidase, which are two enzymes related to the generation of ROS, and upregulates superoxide dismutase and glutathione peroxidase, which are two first-line enzymes of defense against oxygen-free radicals [22].

In $\mathrm{AD}$, curcumin protects against $\mathrm{A} \beta$-induced oxidative stress, prevents the formation and extension of $A \beta$ fibrils, destabilizes $A \beta$ fibrils, inhibits acetylcholinesterase, decreases neuroinflammation, and sequesters transition metals [22]. A variety of structure-activity studies have proven that the three moieties in the chemical structure of curcumin play different roles in its interaction with the $A \beta$ peptide: one of the hydroxyl substitutions in the aromatic end group is necessary for inhibition, while the other one of the hydroxyl substitutions is required for activity. Finally, the diketo chain contributes to the flexibility and correct length between aromatic rings [27]. Curcumin has been extensively evaluated and possesses potential antioxidant and anti-inflammatory activity in AD. The most important mechanism of the anti-inflammatory action of curcumin is based on the inhibition of NF-kB, which leads to the decreased formation of cytochemokines and $A \beta$ fibrils. Other molecular targets inhibited by curcumin are inducible nitric oxide synthase (iNOs), c-Jun N-terminal kinase (JNK) activation, and activating protein-1 (AP-1) [28].

In anticancer therapy, curcumin inhibits oxidative stress, reduces lipid peroxidation and DNA single-strand breakage, inhibits the COX-1 and COX-2 enzymes, suppresses NF-kB activation, and possesses antiproliferative effects. Moreover, it induces apoptosis by targeting mitochondria, and affects tumor protein p53 (p53)-related signaling [22]. The specific molecular targets for curcumin that are therapeutically important in cancer-signaling pathways include cyclin-dependent kinases (CDKs), p53, Ras, phosphoinositide 3-kinase (PI3K), Protein kinase B (Akt), Wnt/ $\beta$-catenin, and mammalian target of rapamycin (mTOR) [29]. During angiogenesis, curcumin can inhibit and/or downregulate the expression of various pro-angiogenic growth factors such as the vascular endothelial growth factor (VEGF), fibroblast growth factor (FGF), and the endothelial growth factor (EGF) [30]. An overview of the molecular targets of curcumin is represented in Figure 7.

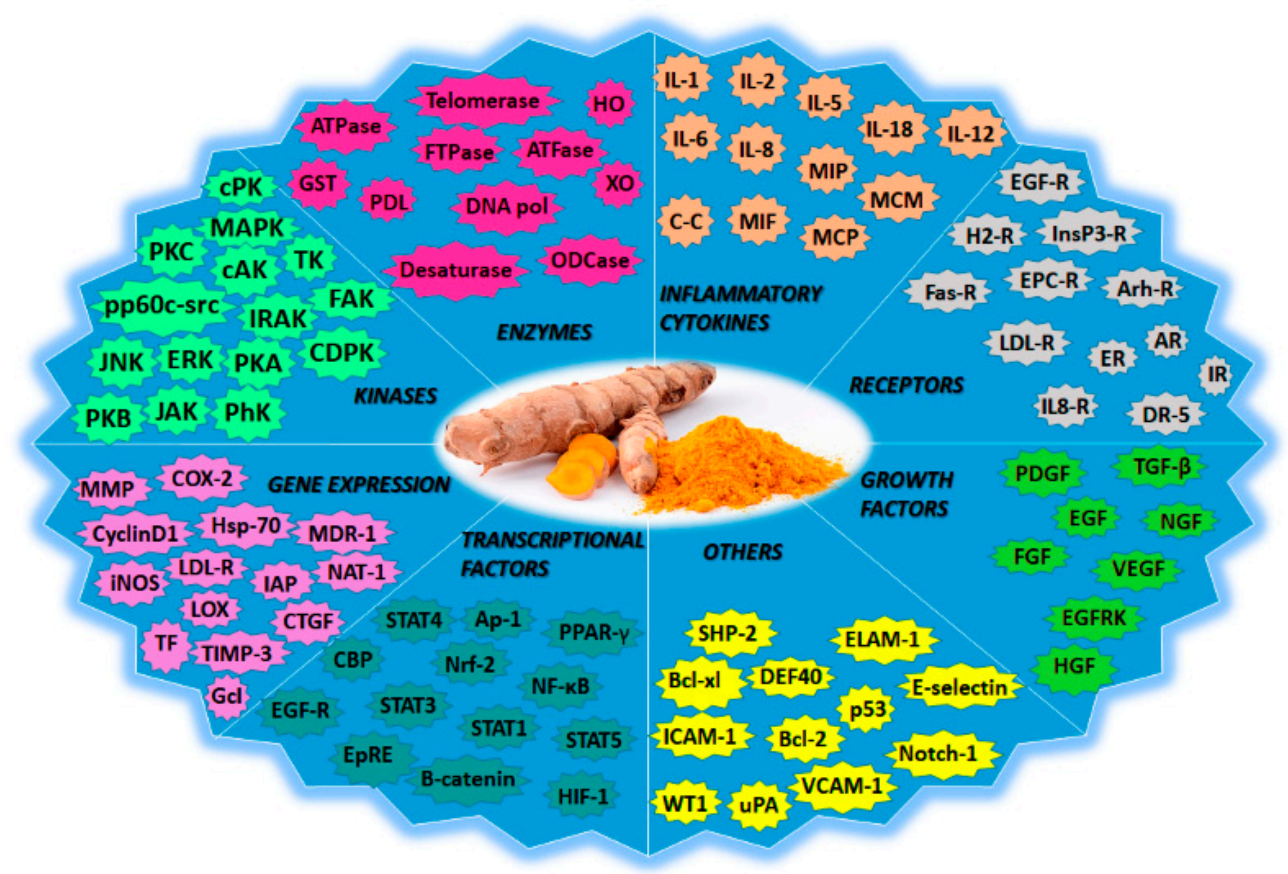

Figure 7. Curcumin is a pleiotropic agent with multiple molecular targets. This molecule could modify the expression of genes, inflammatory cytokines, transcriptional and growth factors, enzymes, and receptors, among others. Adapted with permission from [26]. 2007, Springer Nature. 


\subsection{Effect of Curcumin on Aggregation Protein}

Protein aggregation is the process by which misfolded proteins assume a conformation that cause their polymerization into aggregates and organized fibrils. The adequate aggregation of protein is a precise progression that requires extensive guidance from an excellent control network, which comprises approximately 800 proteins in humans. Many neurodegenerative diseases are associated with inappropriate protein aggregation [31]. These neuronal diseases include disorders in which the aggregates may accumulate in the nucleus, such as for example in polyglutamine expansion diseases (such as spinocerebellar ataxias and Huntington's disease (HD)), which are pathologies that are characterized by inclusions in cytoplasm (for example, $\alpha$-synuclein in PD), disorders in which the aggregates are found outside of the cell (prion diseases), or both intracellularly and extracellularly (such as $\mathrm{A} \beta$ in $\mathrm{AD}$ ) [31].

The effect of curcumin on prion disease has been studied by several authors. Hafner-Bratkovič et al. [32] reported that the binding of curcumin to the $\alpha$-intermediate could block conformational change into the $\beta$-structure, and that the binding of curcumin to prion fibrils could prevent further growth, thus, the formation of new seeds. Similarly, Caughey et al. [33] concluded in their work that curcumin inhibits prion protein resistance (PrP-Res) accumulation in neuroblastoma cells infected with the scrapie agent. In addition, these authors reported the partial inhibition of the conversion of PrP into PrP-res.

Additionally, Pandey et al. [34] analyzed the curcumin effect both in vitro and in cell culture models of $\alpha$-synuclein aggregation. The authors concluded that curcumin induces the inhibition of $\alpha$-synuclein aggregation in a dose-dependent manner. Also, their results suggested that curcumin increased $\alpha$-synuclein solubility in cells containing aggregates.

The oligomerization of $\alpha$-synuclein aggregates is structurally similar to the A $\beta$-protein aggregates of AD. Therefore, curcumin has been investigated as a potential AD treatment. Brahmkhatri et al. [35] reported that curcumin-loaded gold nanoparticles inhibited $A \beta$ aggregation, and that these were capable of dissolving aggregates. Likewise, Mithu et al. [36] reported that curcumin disorganizes $A \beta$ fibrils; the disruption of $A \beta$-fibrils was achieved by means of structural changes in the salt bridge region and near the $C$ terminus. A more detailed report on the inhibition of $A \beta$ aggregation revealed that, besides curcumin inhibiting fibril formation in vitro, it also inhibited the formation of $A \beta$ oligomers and their toxicity in vivo [37].

It has been reported that amyloid formation could be limited by mechanisms such as metal chelation [38], and reducing the induction of the $\beta$-secretase enzyme (BACE1) by proinflammatory cytokines [39]. It has been suggested that BACE1 has a main role in the initiation of the formation of $A \beta$ [40]; therefore, it is an attractive drug target for $A D$. The sequential proteolytic cleavage of the $A \beta$ precursor protein (APP), which is a type I transmembrane protein, produced the formation of $\mathrm{A} \beta$.

Zhang et al. [7] studied the interaction between curcumin and A $\beta$. These authors proposed the modulation of APP levels in the secretory pathway as the cellular mechanism by which curcumin reduces $A \beta$ levels. In addition, they reported that the use of curcumin considerably increased the retention of immature APP in the endoplasmic reticulum. Furthermore, the authors suggested that APP endocytosis could be attenuated by treatment with curcumin.

In order to identify the chemical features that are most important for preventing $A \beta$ accumulation, Reinke et al. [27] examined the effect of three features on the inhibition of amyloid aggregation: the presence of aromatic groups at both extremes of the molecule, the substitution pattern of these aromatics, and the distance and flexibility of the linker section. They demonstrated that the presence of just one single aromatic group did not decrease the protein aggregation; thus, the curcumin efficiency as an aggregation inhibitor could be related to its two phenyl groups. Also, their results suggested that the substitution of these aromatics groups is important for activity, since these are capable of taking part in hydrogen bonding. In addition, the authors reported the approximate distance between the docking sites, which are found between eight and $16 \AA$ from each other; this is similar to the distance between the terminal aromatic regions of curcumin. 


\subsection{Effect of Curcumin in Neuroinflammation}

In recent years, interest in the identification and application of natural compounds that limit neuroinflammation has been growing. The term neuroinflammation has been used to describe several different pathological events, from modifications in the morphology of glial cells to fully fledged tissue invasion and destruction by leukocytes. Neuroinflammation plays a key role in the progression of neurodegenerative diseases and in the invasion of central nervous system (CNS) parenchyma by leukocytes, it is one of its main characteristics, as well as a severe loss of the blood-brain barrier (BBB) integrity [6].

Due to the latter, lymphocytes and myeloid cells express cytokines in the tissue, increasing the inflammatory cascade. Interleukins such as IL-1 $\beta$, IL-6, and IL-23, and cytokines such as TNF, interferon gamma (IFN $\gamma$ ), and granulocyte/macrophage colony-stimulating factor (GM-CSF), chemokines (such as CCL2, CCL5, and CXCL1), secondary messengers (nitric oxide and prostaglandins), and ROS are also mediators for the neuroinflammatory response [41]. The excessive production of these inflammatory mediators could cause neuronal damage and death. It has been demonstrated that curcumin reduces the expression of several inflammatory cytokines, including IL- $1 \alpha$, IL-1 $\beta$, IL-6, TNF, IFN $\gamma$, and many others (Figure 8) [42,43].

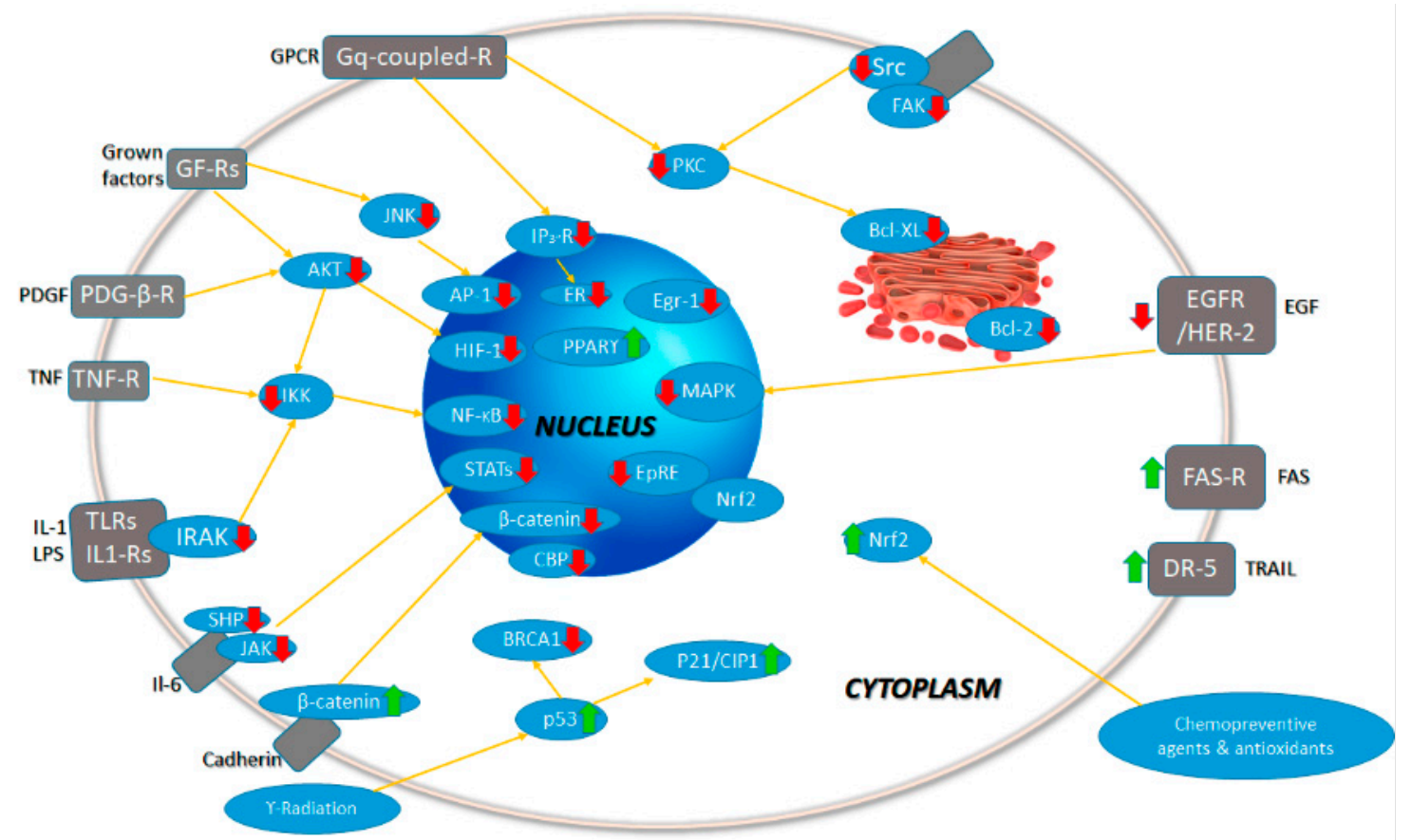

Figure 8. Signaling pathways modulated by curcumin. Up and green arrows indicate the intermediaries upregulated by curcumin; meanwhile, down and red arrows indicate the intermediaries downregulated by curcumin. Adapted with permission from [26]. 2007, Springer Nature.

Some authors have reported that curcumin suppresses the expression of IL- $1 \beta[44,45]$. This mechanism suggests that curcumin inhibits the activation of the Nod-like receptor protein 3 (NLRP3) inflammasome, which is the most characterized inflammasome, and an important innate immune sensor. The NLRP3 inflammasome is activated by an extensive variety of signals of pathogenic, endogenous, and environmental origin. Some authors found that curcumin suppressed inflammation via a strong inhibition of NLRP3-dependent caspase- 1 activation and IL-1 $\beta$ secretion [44].

In the same manner, Devi et al. [46] reported that curcumin could exert a direct effect on constitutive signal transducer and activator of transcription 3 (STAT3) phosphorylation. These authors also mentioned that curcumin is a potent inhibitor of IL- 6 expression in stromal cells. They suggested that this inhibition was related to the I $\kappa B$ kinase (IKK)/NF- $\kappa B$ pathway. Likewise, NF- $\kappa B$ is a ubiquitous 
transcription factor; its activation is linked with the promotion or inhibition of apoptosis, depending on the cell type and condition. Likewise, the inflammatory response induced by TNF- $\alpha$ is strongly linked to the activation of NF-kB.

On the other hand, TNF- $\alpha$ is a very important inflammatory mediator; thus, its reduction is a therapeutic target in several inflammatory diseases [47]. For the interaction of the TNF- $\alpha$ and curcumin, Wang et al. [4] found inhibition in the expression of this factor through downregulating the expression of NF- $\mathrm{kB}$. These authors reported that curcumin reduced the transcription and secretion of TNF- $\alpha$, and also IL-6, which is induced by palmitate, and induces the nuclear translocation of NF- $\mathrm{KB}$ in a concentration-dependent manner [48,49].

Similarly, the suppression of CCL2 function may decrease the attraction of cells of the immune system to the sites of inflammation, which could result in a slowdown of the advancement of inflammation [50]. Zhang et al. [51] investigated the inhibitory effect of curcumin on lipopolysaccharide (LPS)-induced chemokine CCL production. First, these authors induced the upregulation of CCL2 mRNA and protein in C 6 cells, utilizing one $\mu \mathrm{g} / \mathrm{mL}$ of LPS. After this, they probed three doses of curcumin as treatments $(2.5 \mu \mathrm{M}, 10 \mu \mathrm{M}$, and $25 \mu \mathrm{M})$, and found that the expression of CCL2 mRNA decreased with these concentrations in a dose-dependent manner. Moreover, their results suggested that in astrocytoma cells, curcumin induces the downregulation of CCL2 expression through the JNK pathway. However, it appears that CCL2 could be inhibited by curcumin through other pathways besides the JNK pathway. Herman et al. [52] suggested that curcumin downregulates CCL2 activity via the inhibition of protein kinase C (PKC) and matrix metalloproteinases.

On the other hand, IFN- $\gamma$ exerts important effects on epithelial integrity, promotes barrier dysfunction, and increases epithelial permeability through numerous mechanisms. The loss of integrity in BBB is involved in neuronal diseases. For example, Midura-Kiela et al. [53] studied the interaction of IFN- $\gamma$ and curcumin in epithelial cells. They concluded that curcumin induces the inhibition of the signaling of IFN- $\gamma$. Furthermore, curcumin also inhibits the COX-2 pathway. COX-2 is overexpressed in malignant tissues. Accordingly, its inhibition could be a key to cancer and tumor treatments.

\subsection{Effect of Curcumin on Oxidative Stress}

Although oxygen plays an important role in energy production processes in cells (ATP), this molecule could be transformed into very toxic forms in the cells, which are denominated ROS [54]. Antioxidant systems are complex and act in concert to decrease the ROS load. A process known as oxidative stress occurs if an imbalance between ROS and antioxidant systems takes place in favor of oxidants. Oxidative stress has been related to mechanisms leading to neuronal cell injury in various neuronal diseases.

Antioxidants are compounds that can prevent biomolecules from undergoing oxidative damage through free radical-mediated reactions [55]. The majority of the antioxidants present a phenolic group or a $\beta$-diketone group in their structure [56].

To explain the protective properties of phenolic groups in antioxidants, two different mechanisms have been proposed. In the first mechanism (Equation (1)), the free radical becomes a radical by hydrogen atom transfer from the antioxidant $(\mathrm{ArOH})$. This antioxidant activity is related to phenolic $\mathrm{O}-\mathrm{H}$ bond dissociation enthalpy (BDE); thus, if the $\mathrm{O}-\mathrm{H}$ bond attraction is weak, free radical inactivation will be easier.

In the second mechanism, the free radical receives an electron from the antioxidant. The free radical becomes a radical cation, which could be reacting with another antioxidant molecule (Equations (2) and (3)). In terms of this mechanism, the important parameter to analyze for antioxidant activity is the ionization potential (IP). With a low IP, electron abstraction will be easier. In addition to BDE and IP, proton dissociation enthalpy, proton affinity (PA), and electron transfer enthalpy are important factors for evaluating antioxidant activity $[55,57]$.

$$
\mathrm{ArOH}+\mathrm{R}^{*} \rightarrow \mathrm{ArO}^{*}+\mathrm{RH},
$$




$$
\begin{gathered}
\mathrm{ArOH}+R^{*} \rightarrow \mathrm{ArOH}^{*}+R^{-}, \\
\mathrm{ArOH}+R^{-} \rightarrow \mathrm{ArO}^{*}+\mathrm{RH} .
\end{gathered}
$$

As previously mentioned, curcumin possesses a wide range of biological functions, including antioxidant activity. Curcumin contains a variety of functional groups, including phenolic rings that act as electron traps to prevent $\mathrm{H}_{2} \mathrm{O}_{2}$ production and scavenge superoxide radicals, the $\beta$-diketo group that is involved in metal-ligand complexation, and carbon-carbon double bonds (Figure 9) [56,58]; together, these provide the molecule with unique antioxidant properties.

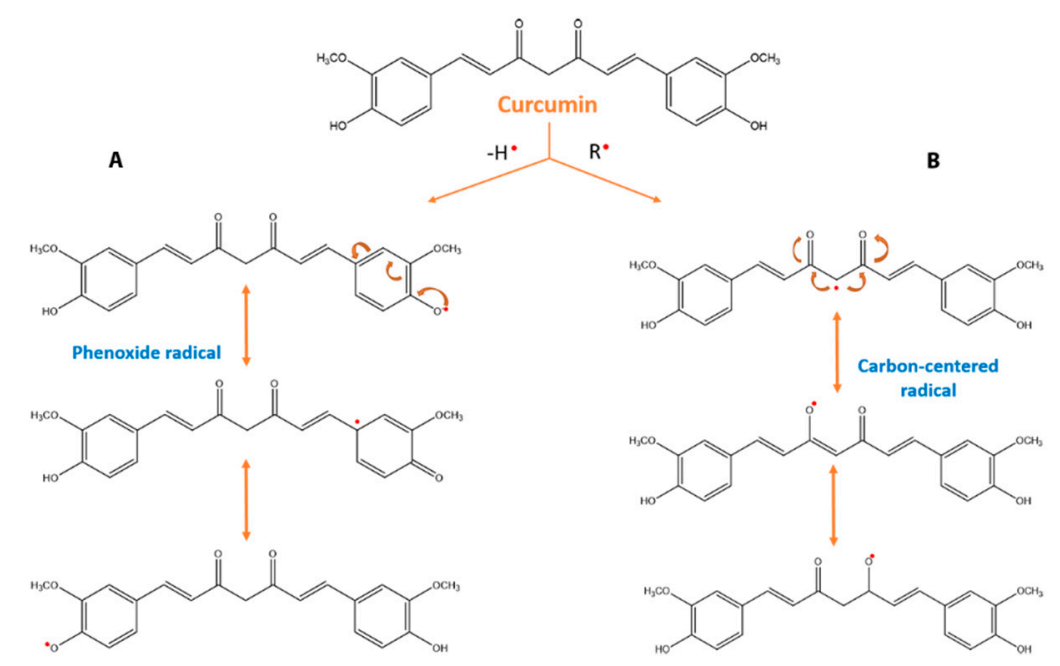

Figure 9. Antioxidant mechanism of curcumin. There are two mechanisms to form phenoxyl radicals. The first mechanism (A) begins by initial electron transfer to the free radical; thus, a radical cation is formed, which produces a phenoxyl radical by a proton loss. The second mechanism (B) is related to direct hydrogen abstraction. Based on the bond dissociation energies, many authors suggest that the most susceptible target for free radicals in curcumin is phenolic $\mathrm{OH}$.

Under acidic to neutral conditions ( $\mathrm{pH}=3-7)$, the keto conformation is the major form. On the other hand, under basic conditions $(\mathrm{pH}>8)$, the enol conformation is predominant, which presents powerful free radical-scavenger properties [59].

Using erythrocyte sedimentation rate (ESR), the reduction of ferric iron in aqueous medium, and intracellular ROS/toxicity assays, Barzegar et al. [60] analyzed the antioxidant properties of curcumin. Their results demonstrated that curcumin confers protection on the cells against the mortal effects of cumene hydroperoxide.

In addition, Zbarsky et al. [58] applied, in the unilateral 6-hydroxydopamine (6-OHDA) rat model of $\mathrm{PD}$, natural compounds, with phenolic groups in their structure to evaluate the neuroprotection level. These authors reported that, with the sub-chronic administration of curcumin, the loss of dopaminergic neurons in the substantia nigra pars compacta was reduced significantly.

The antioxidant protective effect of curcumin was also evaluated against hemin-induced neuronal death. In 2013, González-Reyes et al. [61] evaluated the neuroprotection of curcumin in the primary cultures of the cerebellar granule neurons of rats. They concluded that the use of curcumin as a pretreatment induces antioxidant protection against hemin-induced neuronal death.

The antioxidant effect of curcumin has been evaluated in other applications in addition to neuronal pathologies. For example, Haryuna et al. [62] investigated the antioxidant action of curcumin against oxidative stress caused by diabetes mellitus. These authors worked with cochlear fibroblasts in rat models of diabetes mellitus, and reported that curcumin confers antioxidant protection via the increased expression of superoxide dismutase. These results showed that curcumin presents a wide range of applications. 


\section{Limitation of Chemical Properties and New Proposals}

There are two main limitations when curcumin is formulated for therapeutic purposes: limited solubility in water and low permeability [63]. In addition, the low permeability is related to chemical degradation, a high rate of biotransformation, especially glucuronidation and sulfation [22], and rapid systemic elimination, resulting in low curcumin absorption and poor bioavailability. Therefore, curcumin can be classified as a BCS Class IV molecule. In fact, the majority of oral curcumin is excreted in the feces-about $90 \%$-and the rest in urine (6\%) after 72 hours in rats [64]. Consequently, high doses of curcumin are necessary to produce detectable plasma concentrations. For example, in a human clinical trial, $3.6 \mathrm{~g}$ of curcumin via the oral route was found to produce a plasma curcumin level of $11.1 \mathrm{nmol} / \mathrm{L}$ after one hour of dosing on days one, two, eight, and 29 of the administration [65]. Due to these limitations, novel drug delivery systems have been proposed to increase the bioavailability of curcumin.

\section{New Formulations of Curcumin}

As previously mentioned, one of the reasons that curcumin has poor bioavailability is due to its limited solubility in water; therefore, one of the directions in the development of new formulations for this molecule (as for other lipophilic compounds) is to increase solubility, following strategies such as modification of the solid state, reduction of particle size, the creation of supersaturated solutions, or the encapsulation into nanoparticles. Some new formulations are briefly described later.

Amorphous solid dispersions (ASD) are an interesting strategy of modification of the solid state to improve the rate of dissolution of drugs, and thus their bioavailability. Solid dispersion involves the incorporation of water-insoluble compounds into a hydrophilic carrier matrix. In a study performed by Gangurde et al. [66], the authors demonstrated that curcumin formulated in an Eudragit E (Evonik Nutrition \& Care $\mathrm{GmbH}$, Essen, Germany) polymeric matrix dissolved more rapidly (20-45\% release after $60 \mathrm{~min})$ than curcumin alone $(2-5 \%$ release after $120 \mathrm{~min})$ at $\mathrm{pH} 1.2$. Solubility also was increased: with curcumin alone, solubility was $0.02 \%$, whereas curcumin containing Eudragit E (Evonik Nutrition \& Care $\mathrm{GmbH}$ ) exhibited solubility of $40.29 \%$ and $18.78 \%$ by the spray-drying and rotoevaporation techniques, respectively. In other studies, curcumin revealed an increase of $>1000$ times when it was formulated as ASD in hydroxypropyl methylcellulose matrixes [67].

Nanosuspension is a carrier-free nanoparticle system containing only pure drug crystals, and is sometimes accompanied by a stabilizer. Nanosuspension can greatly increase the saturation solubility as well as the dissolution velocity (by increasing the superficial area). Curcumin has been formulated as a nanosuspension with good results. For example, Wang et al. [68] found an increase in the oral bioavailability of curcumin of about three to four times after the administration of curcumin in nanosuspensions in rats. Similarly, Li et al. [69] found an increase in bioavailability after the intravenous administration of a nanosuspension of about 4.2-fold compared to a curcumin solution.

Self-microemulsifying drug delivery systems (SMEDDS) are isotropic mixtures of oil, hydrophilic surfactant, and co-solvents that rapidly form oil-in-water $(\mathrm{o} / \mathrm{w})$ microemulsion upon gentle agitation followed by dilution in an aqueous medium [70]. This class of supersaturated systems has been effective in increasing the solubility of drugs at the absorption site. Formulated curcumin in SMEDDS has been proposed by Wu et al. [71]. The formulation, which is composed of $20 \%$ ethanol, $60 \%$ Cremophor RH40 (BASF Personal Care and Nutrition GmbH, Monhein, Germany) and 20\% isopropyl myristate, improved the relative oral bioavailability of SMEDDS compared with the curcumin suspension by about $1213 \%$. Similar studies conducted by other researches can be found in the references [72-74].

In addition, the encapsulation of curcumin into nanoparticles not only enhances its bioavailability and solubility (Figure 10), it also increases its stability by protecting it from the influence of the outside environment. 


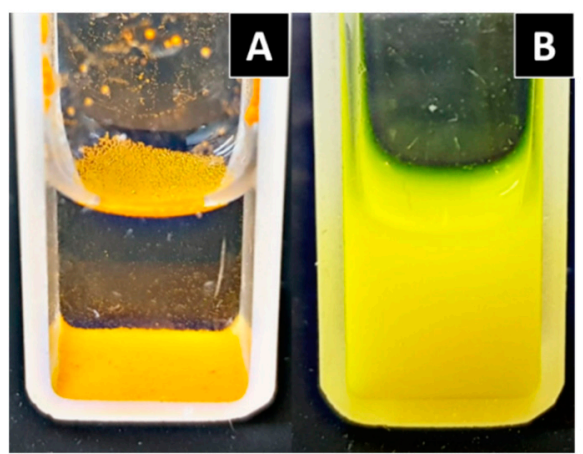

Figure 10. Curcumin solubility: (A) Curcumin showed poor solubility in aqueous medium; (B) the use

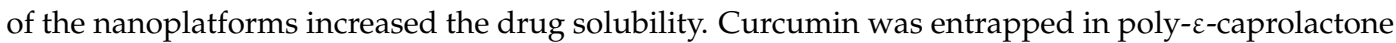
nanoparticles stabilized by Pluronic F68 (Thermofisher, Whaltam, USA), with size of $170 \mathrm{~nm}$ and zeta potential of $-7 \mathrm{mV}$.

Novel curcumin-nanoparticulated delivery approaches, including liposomes, polymeric nanoparticles, solid lipid nanoparticles, polymeric micelles, and others, are emerging as suitable and promising systems. This is because they can be designed and adapted to the desired size, chemical composition, surface charge, and surface functionalization, rendering them potent tools for the treatment of specific diseases such as neurodegenerative disorders and cancer $[75,76]$. In this review, a more detailed description on the development of formulations based on nanoparticles, specifically for neurodegenerative disorders are discussed in the following sections.

\section{Formulations of Curcumin in Nanoparticles}

Nanoparticles for medical purposes comprise a variety of drug transport systems; they traditionally have dimensions of fewer than $200 \mathrm{~nm}$ for brain applications, and are expandable up to $1000 \mathrm{~nm}$, in concept. The small aggregation size confers a high degree of tissue penetration. Nanoparticles for medical and brain purposes are considered non-invasive systems. Although they are designed to flank and cross various tissues, their small size and composition guarantee, in the majority of cases, minimal invasion without risk. The main security provided comprises the chemical composition and the mechanisms of elimination and/or biodegradation. However, several research groups that have delved into this topic have always highlighted the need for a broad assessment in the area of nanotoxicology, because some materials, only by the change of size of aggregation from bulk to nanoparticles can increase their toxicity; contrariwise, other materials exhibit new and better properties.

Conventionally, nanoparticles for medical purposes arise from the combination of two master ideas: from Paul Ehrlich with the concept of magical bullets [77], and Richard Feynman with the notion of miniaturization [78]. However, the materialization of the investigation of new carriers for the transport of drugs to the brain with the use of nanoparticles dates from the first conceptions of Peter Speiser in 1969 [79]. Subsequently, J. Kreuter et al. [80] began the initial assessments on the coating of nanoparticles with polysorbate 80 to facilitate their passage into the CNS. These pioneering works set the standard for the development of polymeric nanoparticles. In parallel, R.H. Müller et al. [81] worked on the development of lipid nanoparticles that would later allow for wide applications in the same area.

The subsequent epochs were accompanied by pharmacokinetic and mechanistic studies at the cellular level with the intention of achieving greater degrees of vectorization. Therefore, some of the examples cited in the application of nanoparticles for the transport of curcumin to the CNS have employed as a strategy the coupling of ligands that permit targeting to the brain. Drug vectorization has advanced substantially, even to the achievement of reaching intranuclear levels in neurons. Some of the most commonly used systems for administering curcumin for the purpose of brain impairment are described below. 


\subsection{Polymeric Nanoparticles}

Polymeric materials were the first to have been used to transport drugs to the brain, and a significant number of curcumin-carrying applications can be found in the literature. Some examples of traditional polymers include poly (butyl cyanoacrylate) (PBCA), poly (lactic-co-glycolic acid) (PLGA), and chitosan. In particular, the synthetic polymers PBCA and PLGA allow adequate control of the particle size, which results in highly reproducible production batches (Figure 11).

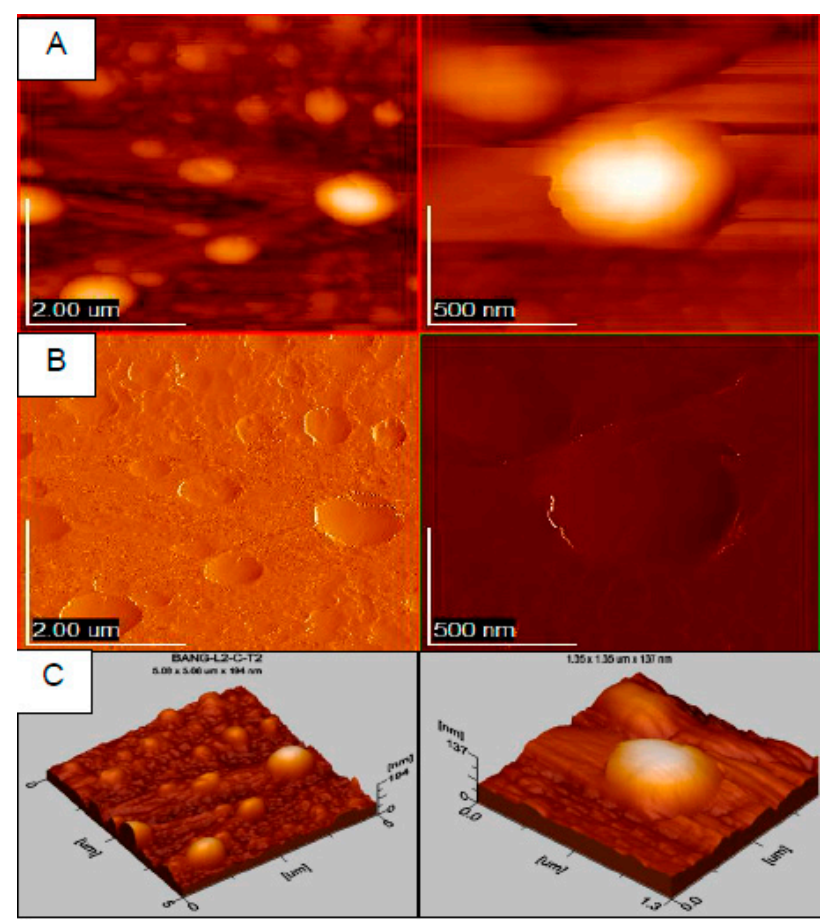

Figure 11. Atomic force microscopy (AFM) microscopy of curcumin poly-e-caprolactone nanoparticles in two magnifications, left and right. Images in AFM (A), 2D (B) and 3D (C) mode.

Subsequent steps have been directed toward the synthesis of new polymers to couple different ligands that can permit adequate vectorization. Usually, these systems allow suitable stability with a zeta potential of at least $-15 \mathrm{mV}$ with polyvinyl alcohol (PVA), while with systems prepared with chitosan, although they appear very promising by the simple and rapid methods of ionic gelation, one of the disadvantages is usually the control of molecular weight. In general, PLGA polymer nanoparticles have shown adequate biocompatibility at the cellular level, and in studies in more complex biological models, even at high amounts up to one $\mathrm{mg} / \mathrm{mL}$ at a cell density of $1 \times 10^{4}$. However, other studies have indicated that the degradation of PLGA could induce cellular damage by the generated acidic medium, although this is restricted to the amount of polymer that was administered [82].

\subsection{Lipid Nanoparticles}

Even when a broad demonstration of the biocompatibility of polymeric systems is available, doubt remains concerning their possible effects in prolonged administrations, due to the possible interactions within the nanometric range with biological systems or accumulation in some tissues. One of the main alternatives to the possible effects deriving from polymers are lipid nanoparticles. This term includes solid lipid nanoparticles and nanostructured lipid carriers. One of the great advantages of these systems is the use of lipids with high biocompatibility and biodegradation. The majority of lipid matrices are constituted of glyceride derivatives that are easily assimilated by our metabolism. We can imagine that several of these are also present in foods, and that they follow the same route of 
biotransformation. Therefore, this aspect is crucial in the choice of the type of nanoparticle matrix for the transport of curcumin, and it is reflected in a considerable percentage of the published information for brain diseases. The majority of production methods employ temperatures above the melting point of the lipids used. One aspect to be considered is the possible stability of lipid nanoparticles in aqueous dispersion and the exchange between polymorphic structures that can promote the expulsion of the drug. Interestingly, some lipids exhibit biological properties in addition to the nutritional aspect, and their applications are enhanced when handled in the nanometer state. Some of these demonstrate novel biological properties due to an increase in interaction with the biological environment, and to the high degree of distribution and penetration in tissues. If this were the case, the new properties that were exhibited can be complemented with the drugs encapsulated in the same system.

\subsection{Liposomes}

Liposomes are spherical vesicles with one or several layers of phospholipids with an internal aqueous compartment. They usually have a size of less than $100 \mathrm{~nm}$. Due to the high percentage of phospholipids, they are also recognized as highly biocompatible and biodegradable systems. The difference with the previous systems, besides the composition, is the type of architecture. Lipid nanoparticles derive from a solid and compact matrix, and the liposomes do not; even there are some variants that confer flexibility to the structure. The development and evaluation of liposomes is evidenced by a long history in pharmaceutical technology. In fact, the first drug approved by the Food and Drug Administration (FDA) in the nano order was with liposomes, i.e., Doxil (Janssen, Titusville, FL, USA) for the treatment of certain types of cancer [83]. The long trajectory in liposome research also confers the establishment of well-implemented industrial processes that facilitate the subsequent development of similar formulations. This is somewhat different from the polymeric and lipid systems, in which there remain critical systems to be reinforced, especially when they involve high agitation speeds.

\subsection{Cyclodextrins}

Cyclodextrins are glucopyranose structures in the form of a glass with a hydrophobic interior and a hydrophilic exterior by the exposure of hydroxyl units [84]. Cyclodextrins can be used to transport drugs to different organs, and can also be derivatized to increase their vectorization. They have shown high biocompatibility for deriving from the starch. Unlike previous systems, cyclodextrins are prefabricated carriers for the direct incorporation of the cargo. In theory, competition is mentioned between the liquid medium inside the vessel and the new molecule that one wishes to enter. Therefore, it is necessary to know the constants of affinity and dissociation. As with a traditional glass, when transported to the table, the interior can spill. In the case of drugs, the cargo may also get in the way. The hydrophobic characteristic allows some lipid extraction at the BBB level, which could also facilitate passage into the brain region. Even in other pathologies, effects can be found with empty cyclodextrins due to the effect generated in lipophilic components.

\subsection{Tools for Drug Targeting of Curcumin}

The BBB is a highly sophisticated barrier that is designed to maintain the integrity and homeostasis of the brain. From a technological point of view, it is a great challenge to direct different carriers toward the brain region under the concept of "non-invasive". Some strategies that have been employed include the surface coupling of the nanoparticles of ligands to specific receptors, the coupling of transporter substrates overexpressed in the $\mathrm{BBB}$, and transport by adsorption through the interaction of opposite electrical charges (negative of the endothelial cell membrane and positive of the carrier). In other situations, various pathologies related with neuroinflammation produce a relative opening of the narrow junctions, therefore increasing the probability of the passage of carriers into the nanoparticle architecture. Intentional opening has not comprised a viable option because of the risk involved. Other strategies include furtive aggressive participation. The use of peptides, some of these from 
virus fragments or modified versions to ensure efficacy without toxicity, is a highly effective option. The transactivating-transduction peptide (TAT) has been a classic example of this type of mechanism.

It is noteworthy that the presence of surface agents substantially modifies the targeting capacity of the curcumin nanoparticles toward the CNS. However, a study in the literature mentions the formulation of PLGA nanoparticles with curcumin obtained by flash nanoprecipitation without a stabilizing agent. These authors demonstrated a 20 -fold reduction in the administered dose compared with bulk curcumin (see Table 1). It is even more important to point out that the majority of the studies mentioned in Table 1, some of these that have been widely extended in biological elucidation mechanisms do not involve the application of highly sophisticated systems. In other brain pathologies, it has become a challenge to possess the most sophisticated. On the other hand, some formulations of curcumin in nanoparticles even include the combination of two active molecules, such as puerarin and dexanabinol. In addition, in the search for multifunctional systems, or theranostics, curcumin has been conjugated in magnetic nanoparticles for the detection of $\mathrm{A} \beta$ plaques in $\mathrm{AD}$ and in combination with gold-iron oxide nanocomposite systems for brain-cancer theranostics (see Table 1 for details).

Table 1. Examples of nanoparticle formulation for transport of curcumin to the brain.

\begin{tabular}{|c|c|c|c|c|c|c|}
\hline Carrier & Composition & Ligand/Stabilizer & Size, PI and $\Psi(\mathrm{mV})$ & $\%$ of EE and DL & Model of Evaluation & Reference \\
\hline \multirow{6}{*}{$\begin{array}{l}\text { Solid lipid } \\
\text { nanoparticles }\end{array}$} & $\begin{array}{l}\text { Polyoxyethylene } \\
\text { stearate, stearic acid }\end{array}$ & Lecithin & $60, \Psi=-21.7$ & $\mathrm{DL}=21.61$ & $\begin{array}{l}\text { Major depression (in vitro } \\
\text { and in vivo models) }\end{array}$ & [85] \\
\hline & $\begin{array}{l}\text { Compritol 888 ATO } \\
\text { (Gattefossé, } \\
\text { Saint-Priest, France) }\end{array}$ & Tween 80 , soya lecithin & 136 & $81.9,92.3$ & $\begin{array}{l}\text { Cerebral ischemic injury } \\
\text { (in vivo model) }\end{array}$ & [86] \\
\hline & Stearic acid & Lecithin, taurocholate & 148 & $\mathrm{EE}=93.2$ & $\begin{array}{l}\text { Huntington's disease } \\
\text { (in vivo model) }\end{array}$ & [87] \\
\hline & Glyceryl monooleate & $\begin{array}{c}\text { Pluronic F-68, vitamin E } \\
\text { TPGS }\end{array}$ & $93, \Psi=-30.9$ & $\mathrm{EE}=65$ & $\begin{array}{l}\text { Rotenone-induced mouse } \\
\text { model of Parkinson's } \\
\text { disease (in vitro and } \\
\text { in vivo models) }\end{array}$ & [88] \\
\hline & $\begin{array}{l}\text { Palmitic acid, } \\
\text { cholesterol }\end{array}$ & $\begin{array}{l}\text { N-trimethyl Chitosan } \\
\text { vitamin E TPGS }\end{array}$ & $412,0.26, \Psi=35.7$ & 93,4 & $\begin{array}{l}\text { Biodistribution (in vitro } \\
\text { and in vivo models) }\end{array}$ & [89] \\
\hline & Compritol 888 ATO & Tween 80 , soya lecithin & 136 & $81.9,92.3$ & $\begin{array}{c}\text { Aluminum-induced } \\
\text { behavioral } \\
\text { (in vivo model) } \\
\end{array}$ & [90] \\
\hline \multirow[t]{3}{*}{$\begin{array}{l}\text { Nanostructured lipid } \\
\text { carriers }\end{array}$} & $\begin{array}{c}\text { Glyceryl } \\
\text { monostearate, soy } \\
\text { lecithin, medium } \\
\text { chain triglycerides }\end{array}$ & Poloxamer 188 & $129,0.25 \Psi=-27.8$ & $95.9,4.21$ & $\begin{array}{l}\text { Pharmacokinetic and } \\
\text { biodistribution } \\
\text { (in vivo model) }\end{array}$ & [93] \\
\hline & $\begin{array}{l}\text { Phosphatidyl choline, } \\
\text { cholesterol oleate, } \\
\text { glycerol trioleate }\end{array}$ & Lactoferrin & 103.8, $\mathrm{PI}=0.15, \Psi=-5.80$ & $96.51,2.60$ & $\begin{array}{l}\text { Alzheimer's disease } \\
\text { (in vitro and } \\
\text { in vivo models) }\end{array}$ & [94] \\
\hline & $\begin{array}{l}\text { PC, cholesterol oleate, } \\
\text { glycerol trioleate }\end{array}$ & Polysorbate 80 & $90.5,0.14, \Psi=-20.3$ & $\mathrm{EE}=94.39, \mathrm{DL}=3.29$ & $\begin{array}{l}\text { Biodistribution (in vitro } \\
\text { and in vivo models) }\end{array}$ & [95] \\
\hline \multirow{7}{*}{$\begin{array}{l}\text { Polymeric } \\
\text { nanoparticles }\end{array}$} & PLGA & Lipid monolayer & 193.4, $\mathrm{PI}=0.115, \Psi=-43.8$ & $13.23,2.31$ & $\begin{array}{l}\text { Inflammation model } \\
\text { (in vitro model) }\end{array}$ & [96] \\
\hline & PLGA & PVA & $163,0.053, \Psi=-12.5$ & $\mathrm{EE}=46.9$ & $\begin{array}{l}\text { Pharmacokinetic } \\
\text { (in vivo model) }\end{array}$ & [100] \\
\hline & PLGA & - & - & - & $\begin{array}{l}\text { Opioid tolerance and } \\
\text { dependence } \\
\text { (in vivo model) }\end{array}$ & [101] \\
\hline & Chitosan & Tween 80 & $10, \Psi=-16.8$ & - & $\begin{array}{l}\text { Arsenic toxicity } \\
\text { (in vivo model) }\end{array}$ & [102] \\
\hline & Chitosan-alginate & - & 50 & - & Epilepsy (in vivo model) & [103] \\
\hline & Chitosan & Bovine serum albumin & $143.5,0.021, \Psi=-10.8$ & $\mathrm{EE}=95.4$ & $\begin{array}{l}\text { Phagocytosis of the } \mathrm{A} \beta \\
\text { peptide (in vitro model) }\end{array}$ & [104] \\
\hline & PLGA & PVA & $200, \Psi=-19$ & $\mathrm{EE}=77$ & $\begin{array}{l}\text { Neurogenesis (in vitro } \\
\text { and in vivo models) }\end{array}$ & [105] \\
\hline
\end{tabular}


Table 1. Cont

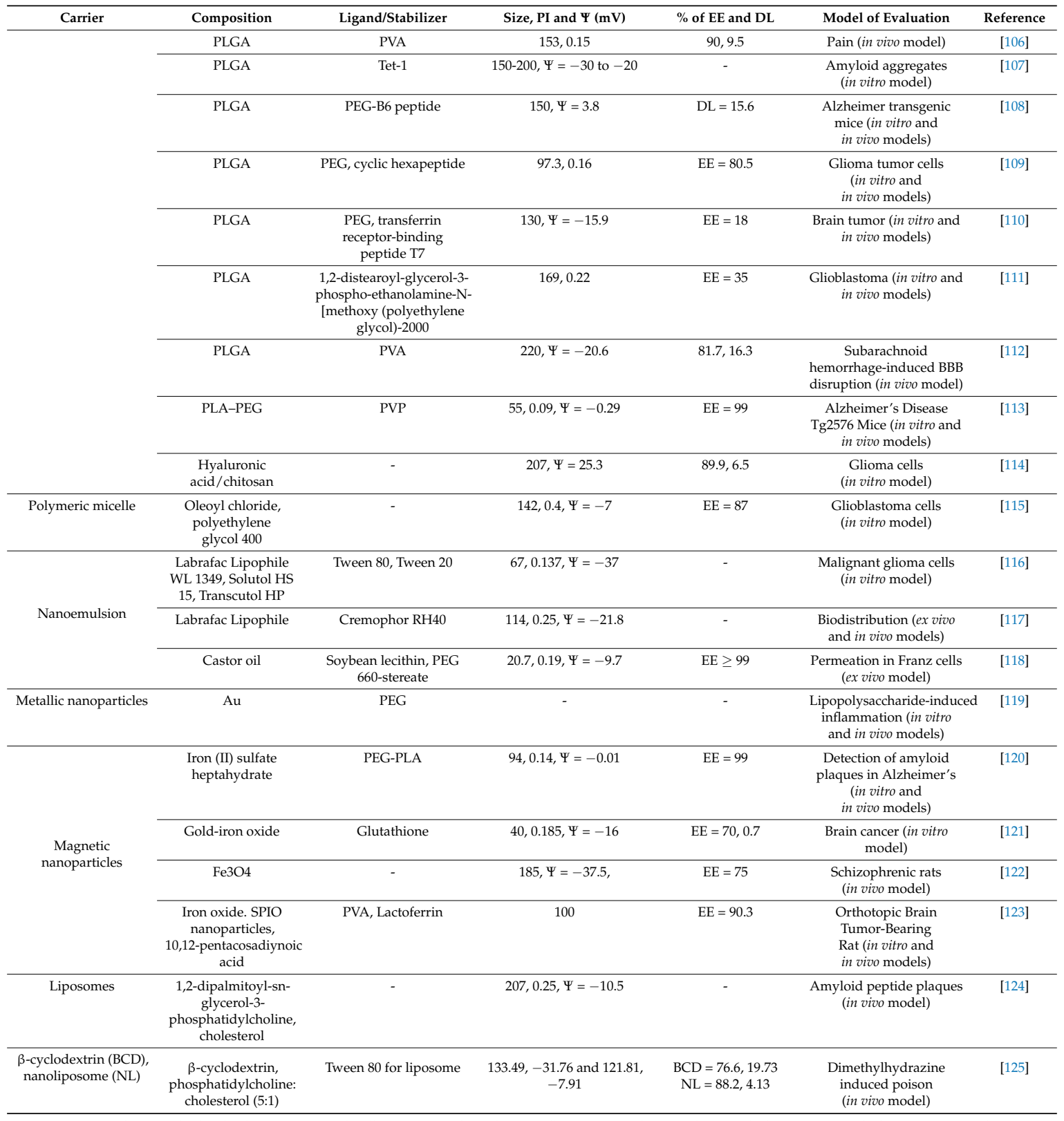

PVA: polyvinyl alcohol, PLGA: poly (lactic-co-glycolic acid), PVP: polyvinylpyrrolidone, PI: polidispersity index, PEG: polyethylene glycol, EE: entrapment efficiency, DL: drug load, D- $\alpha$-tocopheryl polyethylene glycol 1000 Succinate: vitamin E TPGS, CNS: central nervous system, BBB: blood-brain barrier.

\section{Applications of Curcumin in Nanoparticles}

\subsection{Alzheimer's Disease}

Alzheimer's disease is the most frequent neurodegenerative disorder worldwide; it is characterized by extracellular $A \beta$ aggregation, intracellular neurofibrillary tangles, tau hyperphosphorylation, and progressive neuron loss. Its main clinical features are memory loss, behavioral changes, and cognitive impairment [126,127]. At present, the limited efficacy of the available therapies has encouraged the search for new treatments. In this regard, recent investigations undertaken in diverse experimental models have suggested that curcumin could be helpful for $\mathrm{AD}$ treatment. However, limitations in the bioavailability of curcumin have hindered its use 
and promoted the search for suitable vehicles to improve its pharmacological activity, such as nanoparticle formulations.

In recent years, the development of nanocarriers to transport curcumin to the brain in AD models has increased considerably; however, the efficacy, safety, and suitability of these formulations is still a main concern. Thus, in addition to the cellular uptake, the evaluation of cell viability has become pivotal to demonstrate the biocompatibility of these formulations.

It has been suggested that aluminum is involved in the etiology of AD; thus, in an early study, the neuroprotective effect of solid lipid nanoparticles loaded with curcumin (SLN-Cur) was proved in an AD mouse model induced by $100 \mathrm{mg} / \mathrm{kg}$ of aluminum chloride [91]. The results showed that treatment with SLN-Cur $(50 \mathrm{mg} / \mathrm{kg}$ ) produced a $73 \%$ recovery in acetylcholinesterase and a $97.46 \%$ recovery in membrane lipids with respect to the group treated with aluminum chloride alone. In addition, mice treated with SLN-Cur underwent less learning impairment and cognition loss, as measured by the Morris water maze test, which suggests the potential of SLN-Cur as an alternative therapeutic for AD.

Similarly, evidence for a reduction of neurogenesis in AD has been shown, which suggests that the induction of this neuronal process mediated by endogenous neuronal stem cells (NSC) would be a probable therapeutic target. In this regard, Tiwari et al. [105] explored the effect of PLGA nanoparticles loaded with curcumin (PLGA-NP-Cur) on neuronal differentiation and NSC proliferation. Through transmission electron microscopy (TEM) analysis, these authors showed that PLGA-NP-Cur had the ability to internalize into NSC derived from the hippocampus. Moreover, Alamar blue reduction and MTT assays suggested that PLGA-NP-Cur $(0.001-50 \mu \mathrm{M})$ increased NSC proliferation and cell viability, with the highest effect at $0.5 \mu \mathrm{M}$. It is noteworthy that bulk curcumin enhanced NSC proliferation only at $0.5 \mu \mathrm{M}$, whereas PLGA-NP-Cur significantly increased NSC proliferation at much lower doses $(0.001 \mu \mathrm{M}, 0.01 \mu \mathrm{M}, 0.1 \mu \mathrm{M}$, and $0.2 \mu \mathrm{M})$. Likewise, the results demonstrated that PLGA-NP-Cur reversed deficits in hippocampal neurogenesis and in learning and memory dysfunction in an AD rat model induced by the brain injection of Aß. Interestingly, a more pronounced effect was exhibited by PLGA-NP-Cur when compared with bulk curcumin. Collectively, the results suggested that PLGA-NP-Cur could offer an alternative for the treatment of AD and regenerative medicine.

On the other hand, diverse evidences suggest that oxidative stress participates in the pathophysiology of AD; thus, Djiokeng Paka et al. [128] evaluated the antioxidant and anti-inflammatory activities of curcumin-loaded PLGA nanoparticles (Cur-PLGA-NP) in SK-N-SH cells, which are human neuroblastoma-derived cells. Through assays of radical scavenging activity, the authors found that Cur-PLGA-NP exhibited 1.5-fold and 2.2-fold greater antioxidant activity against peroxyl radical than curcumin alone and empty NP, respectively. They also showed that Cur-PLGA-NP prevented Tau phosphorylation and Akt activity, which have been shown as altered in AD brains. Therefore, the authors suggested that Cur-PLGA-NP could be potentially useful for treating AD.

In another study, Meng et al. [94] developed a low-density lipoprotein-mimic nanocarrier attached to lactoferrin encapsulated in curcumin (Lf-mNLC-Cur) and evaluated its effect on the progression of disease in a rat model of $\mathrm{AD}$. The rat model was generated by means of an intraperitoneal injection of $\mathrm{D}$-gal $\left(0.3 \mathrm{~mL} / 100 \mathrm{~g} / \mathrm{d}\right.$ for six weeks) and a bilateral injection of $\mathrm{A} \beta_{1-42}$ in the dorsal hippocampus (one $\mathrm{mg} / \mathrm{mL} ; 5 \mu \mathrm{L}$ ). Through fluorescence images, it was shown that Lf-mNLC-Cur had the ability to cross the $\mathrm{BBB}$, to penetrate into the brain, and to release curcumin. In order to evaluate the therapeutic effect of the formulation, histological preparations to examine the state of the nerve cells in the hippocampal region after the administration of Lf-mNLC-Cur and measurements of malondialdehyde (MDA) in blood were performed. Hematoxylin-eosin staining revealed a lower damage in the treatment with Lf-mNLC-Cur, and the content of MDA was reduced with respect to the control, which suggested that the formulation was effective for decreasing the oxidative stress associated with the progression of AD [94].

Similarly, Barbara et al. [129] designed and engineered a curcumin-encapsulated PLGA nanoparticle bound to peptide g7 (Cur-NP-g7) to promote BBB crossing. The authors demonstrated that Cur-NP-g7 can internalize hippocampal neurons, and that concentrations to around $200 \mu \mathrm{M}$ were 
not toxic. Furthermore, the authors determined the effect of Cur-NP-g7 on A $\beta$ aggregation, employing an in vitro AD model generated in the primary hippocampal culture derived from the rat brain. The results revealed an important decrease of $A \beta$; thus, they concluded that their formulation represent a promising tool for the treatment of AD.

On the other hand, a recent study demonstrated the anti-inflammatory effects of curcumin-loaded spherical polymeric nanoparticles (Cur-SPN). In that study, it was demonstrated that Cur-SPN (10 $\mu \mathrm{M})$ reduced cytokines IL-1ß, IL-6, and TNF- $\alpha$ expression in macrophages stimulated by A $\beta$ fibrils $(2 \mu \mathrm{M})$. Likewise, cell viability assays revealed that Cur-SPN did not induce apoptosis, and no evidence of toxicity was detected. Based on their findings, the authors claimed that this approach could be helpful for the amelioration of inflammation observed in AD [94].

In a study undertaken by Huang et al. [130], PLGA nanoparticles were designed conjugated with the $S 1$ peptide (an inhibitor of $A \beta$ generation), brain-targeting calreticulin (CRT) (a peptide that binds to the transferrin receptor), and curcumin (as a therapeutic substance to tackle the disorder). The results revealed that the nanocarrier (S1-CRT-NP+Cur) was taken up into a cellular model of the BBB (brain microvascular bEnd.3 cells), suggesting that it can permeate across the BBB. In support of this hypothesis, S1-CRT-NP+Cur was distributed in mouse brain after intravenous administration, as demonstrated by in vivo bioluminescence imaging system and post-mortem studies. The therapeutic effect of S1-CRT-NP+Cur was explored by means of a Y-maze and a new object recognition test, the determination of astrogliosis and microgliosis, and the measurement of cytokines, superoxide dismutase (SOD), and ROS levels in a transgenic AD mouse model (APP/PS1dE9). Interestingly, S1-CRT-NP+Cur attenuated cognitive deficits, reduced astrogliosis and microgliosis, increased the number of synapses, decreased inflammatory cytokines, enhanced SOD levels, and reduced ROS levels. These findings highlight S1-CRT-NP+Cur as a promising approach for future use in AD treatment.

Finally, in a recent report, PLGA-PEG nanoparticles attached to the B6 peptide with curcumin encapsulated (PLGA/PEG-B6-Cur) were designed [108]. PLGA-PEG was employed to enhance the bioavailability, and the B6 peptide was employed to permit BBB crossing. In order to explore their potential usefulness in AD treatment, PLGA/PEG-B6-Cur were proven in HT22 cells and an AD rodent model (APP/PS1 transgenic mice). Cytotoxicity studies in HT22 cells demonstrated that PLGA/PEG-B6-Cur did not affect cell viability up to $500 \mu \mathrm{g} / \mathrm{mL}$. To evaluate the effect of PLGA/PEG-B6-Cur on memory capability and spatial learning, the Morris water maze test was performed in animals intraperitoneally injected with the nanocarrier. The experimental results revealed that PLGA/PEG-B6-Cur significantly improved cognitive performance, which correlated with a decrease in tau phosphorylation and $A \beta$ production in the hippocampus. Altogether, these findings suggest that PLGA/PEG-B6-Cur may represent a promising alternative for treating AD.

\subsection{Parkinson's Disease}

Parkinson's disease is the second most frequent neurodegenerative disorder and is characterized by abnormalities in the control of voluntary movements. The pathological hallmarks of PD include neuronal cell death, oxidative stress, mitochondrial dysfunction, and the accumulation of $\alpha$-synuclein. The gold standard for the treatment of PD is L-Dopa; however, its chronic employment leads to a severe collateral problem known as dyskinesia. Therefore, the lack of a permanent cure has triggered the search for novel treatments. In this respect, curcumin has shown good effects in different experimental models; thus, it could be a key molecule for developing new strategies to reach a definitive treatment.

In this regard, in a first approach, alginate-curcumin nanoparticles (Alg-NP-Cur) were developed, and their probable therapeutic actions were evaluated in a PD Drosophila model. Alg-NP-Cur exhibited antioxidant power by the reduction of the lipid peroxidation in the PD Drosophila brain after a diet supplemented with the nanocarrier for 24 days. The effective prevention of the progression of the Parkinsonian symptoms in the PD flies was evidenced by the inhibition of the loss of climbing ability in flies with respect to PD flies without exposure to Alg-NP-Cur. Therefore, this report provided a rationale for employing curcumin-encapsulated nanoparticles in preclinical and clinical studies [131]. 
In this respect, in another study, Kundu et al. [88] designed glyceryl monooleate nanoparticles loaded with piperine and curcumin (GMO-NP-Pip/Cur). The anti-aggregate and anti-fibrillar effects of GMO-NP-Pip/Cur on $\alpha$-synuclein oligomers were evaluated employing atomic force microscopy (AFM). The results showed that GMO-NP-Pip/Cur produced a pronounced inhibition of $\alpha$-synuclein aggregation. Similarly, GMO-NP-Pip/Cur were able to ameliorate motor dysfunction when co-administered with rotenone in a PD mouse model. Interestingly, GMO-NP-Pip/Cur exhibited anti-apoptotic and antioxidant activities with no evidence of cytotoxicity. Therefore, GMO-NP-Pip/Cur could be an interesting approach for the treatment of PD.

In another study, Bollimpelli et al. [132] elaborated lactoferrin nanoparticles by sol-oil chemistry, which were loaded with curcumin (Lf-NP-Cur). The potential neuroprotective usefulness of this formulation was evaluated against toxicity induced by rotenone in SK-N-SH cells, employing microscopy, a lactate dehydrogenase (LDH) release assay, and an MTT assay. The findings suggested that Lf-NP-Cur protect the cells from the toxicity of rotenone, more than curcumin alone; thus, these may be a suitable drug-delivery strategy against PD.

Finally, nanoparticles with Polysorbate 80 are widely used to improve the BBB permeability of the nanoparticles; thus, Zhang et al. [133] developed curcumin-loaded polysorbate 80-modified cerasomes (PS80-NP-Cur). The formulation was able to modify the release time of curcumin monitored in C57BL/ 6 mice, producing a prolonged circulation time in the blood. Furthermore, PS80-NP-Cur produced a remarkable reduction of PD symptoms in a PD mouse model induced by 1-methyl-4-phenyl-1,2,3,6-tetrahydropyridine (MPTP), when these were administered concomitantly with ultrasound-targeted microbubble destruction (UTMD). Despite these promising results, the utilization of techniques such as UTMD should be evaluated to a greater extent, because its employment for prolonged times could lead to severe undesirable effects.

\subsection{Huntington's Disease}

Huntington's disease is a genetic neurodegenerative disorder whose clinical manifestations include involuntary movements and anxiety. To date, there is no specific medication to treat the disease; however, since mitochondrial impairment appears to contribute to neuronal death in HD, approaches to decrease mitochondrial dysfunction could represent a therapeutic alternative. In this regard, it has been reported that dietary curcumin possesses beneficial effects in HD. Therefore, Sandhir et al. [87] fabricated solid lipid nanoparticles loaded with curcumin (SLNP-Cur) and explored their neuroprotective effectiveness in a HD rat model induced by 3-nitropropionic acid (3-NP). The administration of SLNP-Cur was able to restore SOD activity and glutathione levels. Furthermore, SLNP-Cur decreased ROS, protein carbonyls, and lipid peroxidation. In addition, the formulation reduced the motor impairment induced by the treatment with 3-NP. Therefore, these results indicate that SLNP-Cur could be helpful for the treatment of HD.

\section{Conclusions}

Curcumin is an example of an ancestral phytochemical whose health benefits have been confirmed and new applications have been discovered with a high impact for incurable diseases. The study of curcumin is one of the few cases of broad applications demonstrated under methodological principles and in a reproducible manner. Recently, the greatest impacts of this molecule are due to the novel technological proposals for its biological administration. In particular, the use of nanoparticles has made it possible to demonstrate benefits at the brain level, which can even revolutionize medicine. However, as with any chemical substance, it is convenient to emphasize toxicity issues in order to ensure the safety of all clinical trials. In addition to the clear results in brain models, the increase in benefits can be addressed with an improvement in the functioning of nanotechnological carriers.

Author Contributions: Conceptualization, G.L.-G. and H.C.; Methodology, M.L.D.P.-A.; Software, J.A.M.-T.; Validation, B.F., M.G.-T. and I.H.C.-F.; Formal Analysis, M.L.D.P.-A.; Investigation, I.H.C.-F., N.M.-M.; 
Writing-Original Draft Preparation, N.M.-M., M.L.D.P.-A., G.L.-G., H.C.; Writing-Review and Editing, M.L.D.P.-A., G.L.-G., H.C.; Visualization, G.L.-G.; Supervision, G.L.-G. and H.C.

Funding: This research was funded by Dirección General de Asuntos del Personal Académico, Universidad Nacional Autónoma de México (Becas Posdoctorales, PAPIIT TA 200318), Consejo Nacional de Ciencia y Tecnología, 526864 .

Acknowledgments: The authors would like to thank Carlos Flores-Morales for his assistance with AFM assessment, Miguel Ángel Canseco-Martínez for the help providing FTIR analysis, Karla Eriseth Reyes-Morales for her technical assistance with thermal tests.

Conflicts of Interest: The authors declare no conflict of interest. The funders had no role in the design of the study; in the collection, analyses, or interpretation of data; in the writing of the manuscript, or in the decision to publish the results.

\section{Abbreviations}

\begin{tabular}{|c|c|}
\hline $\mathrm{AD}$ & Alzheimer disease \\
\hline AP-1 & activating protein- 1 \\
\hline $\mathrm{APP}$ & amyloid- $\beta$ precursor protein \\
\hline AR & androgen receptor \\
\hline Arh-R & aryl hydrocarbon receptor \\
\hline AS & $\alpha$-synuclein \\
\hline ASD & Amorphous solid dispersions \\
\hline$A \beta$ & amyloid- $\beta$ \\
\hline BACE1 & $\beta$-secretase enzyme \\
\hline BBB & blood-brain barrier \\
\hline BCS & Biopharmaceutics Classification System \\
\hline cAK & autophosphorylation-activated protein kinase \\
\hline CBP & CREB-binding protein \\
\hline CDPK & $\mathrm{Ca}^{2+}$-dependent protein kinase cellular src kinase \\
\hline CNS & central nervous system \\
\hline COX-2 & cyclooxygenase- 2 \\
\hline cPK & protamine kinase \\
\hline CTGF & connective tissue growth factor \\
\hline DFF40 & DNA fragmentation factor; $40-\mathrm{kd}$ subunit \\
\hline DL & drug loading \\
\hline DR-5 & death receptor-5 \\
\hline EE & entrapment efficiency \\
\hline EGF & epidermal growth Factor \\
\hline EGF-R & EGF receptor \\
\hline EGFRK & EGF receptor-kinase \\
\hline Egr-1 & early growth response gene- 1 \\
\hline ELAM-1 & endothelial leukocyte adhesion molecule-1; Bcl-2, B-cell lymphoma protein 2 \\
\hline EPC-R & endothelial protein C-receptor \\
\hline EpRE & electrophile \\
\hline ERK & extracellular receptor kinase \\
\hline ER- $\alpha$ & estrogen receptor- $\alpha$ \\
\hline FAK & focal adhesion kinase \\
\hline Fas-R & Fas receptor \\
\hline FDA & Food and Drug Administration \\
\hline FGF & fibroblast growth factor \\
\hline FPTase & farnesyl protein transferase \\
\hline $\mathrm{Gcl}$ & Glutamate-cysteine ligase \\
\hline GM-CSF & granulocyte-macrophage colony-stimulating factor \\
\hline GST & glutathione-S-transferase \\
\hline $\mathrm{H} 2-\mathrm{R}$ & histamine (2)-receptor \\
\hline
\end{tabular}




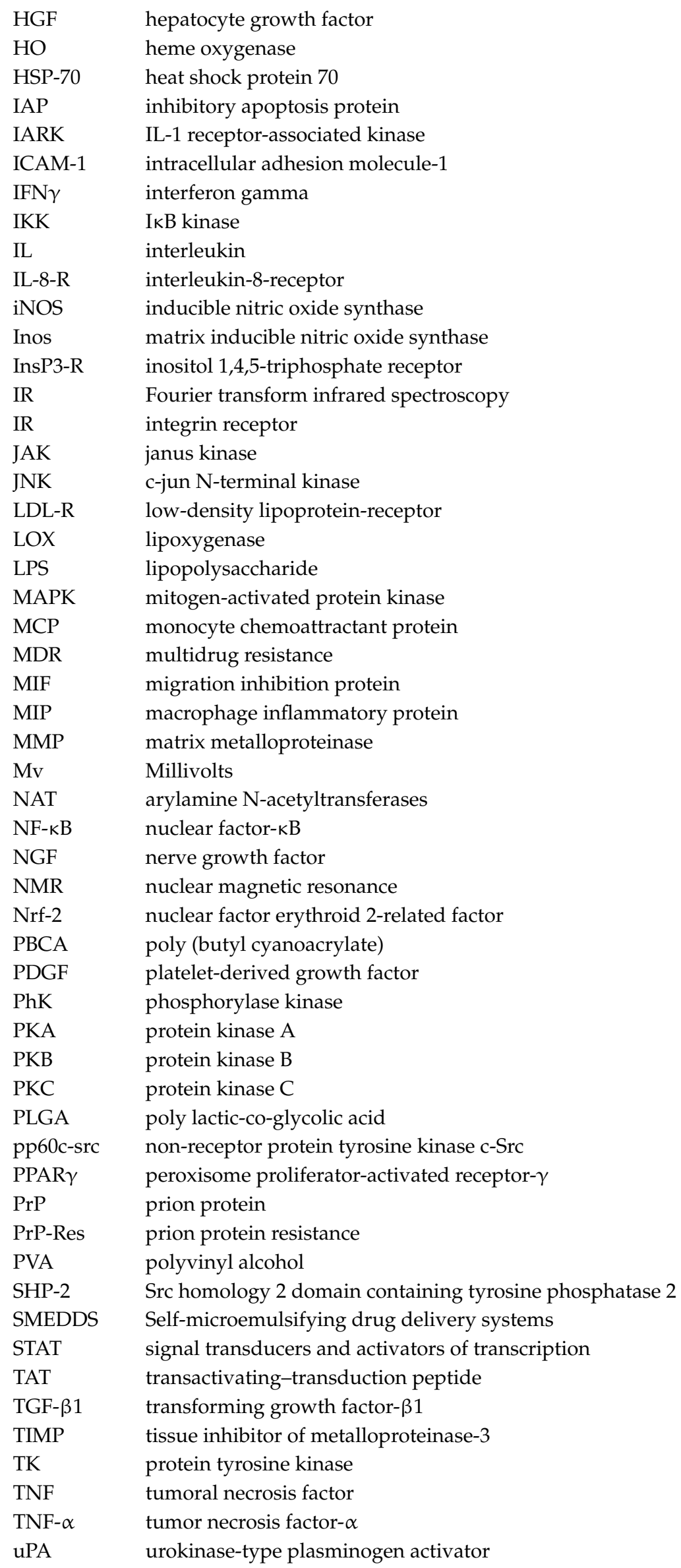


VCAM-1 vascular cell adhesion molecule-1

VEGF vascular endothelial growth factor

$\Psi \quad$ zeta potential

\section{References}

1. Aggarwal, B.B.; Harikumar, K.B. Potential therapeutic effects of curcumin, the anti-inflammatory agent, against neurodegenerative, cardiovascular, pulmonary, metabolic, autoimmune and neoplastic diseases. Int. J. Biochem. Cell Biol. 2009, 41, 40-59. [CrossRef] [PubMed]

2. Alsamydai, A.; Jaber, N. Pharmacological aspects of curcumin: Review article. Int. J. Pharmacogn. 2018, 5, 313-326.

3. Bengmark, S. Curcumin, an atoxic antioxidant and natural NFkB, cyclooxygenase-2, lipooxygenase, and inducible nitric oxide synthase inhibitor: A shield against acute and chronic diseases. J. Parenter. Enter. Nutr. 2006, 30, 45-51. [CrossRef]

4. Wang, S.L.; Ying, L.; Ying, W.; Chen, Y.F.; Na, L.X.; Li, S.T.; Sun, C.H. Curcumin, a potential inhibitor of Up-regulation of TNF-alpha and IL-6 induced by palmitate in 3T3-L1 adipocytes through NF- $\mathrm{kB}$ and JNK pathway. Biomed. Environ. Sci. 2009, 22, 32-39. [CrossRef]

5. Guo, Y.Z.; He, P.; Feng, A.M. Effect of curcumin on expressions of NF-кBp65, TNF- $\alpha$ and IL-8 in placental tissue of premature birth of infected mice. Asian Pac. J. Trop. Med. 2017, 10, 175-178. [CrossRef] [PubMed]

6. Becher, B.; Spath, S.; Goverman, J. Cytokine networks in neuroinflammation. Nat. Rev. Immunol. 2017, 17, 49-59. [CrossRef] [PubMed]

7. Zhang, C.; Browne, A.; Child, D.; Tanzi, R.E. Curcumin decreases amyloid- $\beta$ peptide levels by attenuating the maturation of amyloid- $\beta$ precursor protein. J. Biol. Chem. 2010, 285, 28472-28480. [CrossRef]

8. Fonseca-Santos, B.; Gremião, M.P.; Chorilli, M. Nanotechnology-based drug delivery systems for the treatment of Alzheimer's disease. Int. J. Nanomed. 2015, 10, 4981-5003. [CrossRef]

9. Li, J.; Sabliov, C. PLA/PLGA nanoparticles for delivery of drugs across the blood-brain barrier. Nanotechnol. Rev. 2013, 2, 241-257. [CrossRef]

10. Bhatia, S. Nanoparticles types, classification, characterization, fabrication methods and drug delivery applications. In Natural Polymer Drug Delivery Systems; Nanoparticles, Plants, and Algae; Springer International Publishing: Cham, Switzerland, 2016; pp. 33-85.

11. Priyadarsini, K. The Chemistry of Curcumin: From Extraction to Therapeutic Agent. Molecules 2014, 19, 20091-20112. [CrossRef]

12. Payton, F.; Sandusky, P.; Alworth, W.L. NMR study of the solution structure of curcumin. J. Nat. Prod. 2007, 70, 143-146. [CrossRef] [PubMed]

13. Yanagisawa, D.; Shirai, N.; Amatsubo, T.; Taguchi, H.; Hirao, K.; Urushitani, M.; Morikawa, S.; Inubushi, T.; Kato, M.; Kato, F.; et al. Relationship between the tautomeric structures of curcumin derivatives and their A $\beta$-binding activities in the context of therapies for Alzheimer's disease. Biomaterials 2010, 31, 4179-4185. [CrossRef] [PubMed]

14. Chen, Y.; Wu, Q.; Zhang, Z.; Yuan, L.; Liu, X.; Zhou, L. Preparation of curcumin-loaded liposomes and evaluation of their skin permeation and pharmacodynamics. Molecules 2012, 17, 5972-5987. [CrossRef] [PubMed]

15. Subramani, P.A.; Panati, K.; Lebaka, V.R.; Redd, D.D.; Narala, V.R. Nanostructures for curcumin delivery: Posibilities and challenges. In Nano and -Micro Drug Delivery Systems; Andrew, W., Ed.; Elsevier Science Ltd Desing and Fabrication: Amsterdam, The Netherlands, 2017; pp. 393-418.

16. Kharat, M.; Du, Z.; Zhang, G.; Mcclements, D.J. Physical and Chemical Stability of Curcumin in Aqueous Solutions and Emulsions: Impact of $\mathrm{pH}$, Temperature, and Molecular Environment. J. Agric. Food Chem. 2017, 65, 1525-1532. [CrossRef] [PubMed]

17. Sharma, K.; Agrawal, S.S.; Gupta, M. Development and validation of UV spectrophotometric method for the estimation of curcumin in bulk drug and pharmaceutical dosage forms. Int. J. Drug Dev. Res. 2012, 4, 375-380.

18. Benassi, R.; Ferrari, E.; Lazzari, S.; Spagnolo, F.; Saladini, M. Theoretical study on Curcumin: A comparison of calculated spectroscopic properties with NMR, UV-vis and IR experimental data. J. Mol. Struct. 2008, 892, 168-176. [CrossRef] 
19. Athira, G.K.; Jyothi, A.N. Preparation and characterization of curcumin loaded cassava starch nanoparticles with improved cellular absorption. Int. J. Pharm. Pharm. Sci. 2014, 6, 171-176.

20. O'Neil, M.J. (Ed.) The Merck Index, An Encyclopedia of Chemicals, Drugs, and Biologicals, 15th ed.; Royal Society of Chemistry: Cambridge, UK, 2013.

21. Doktorovova, S.; Souto, E.B.; Silva, A.M. Hansen solubility parameters (HSP) for prescreening formulation of solid lipid nanoparticles (SLN): In Vitro testing of curcumin-loaded SLN in MCF-7 and BT-474 cell lines. Pharm. Dev. Technol. 2018, 23, 96-105. [CrossRef]

22. Shen, L.; Ji, H.F. The pharmacology of curcumin: Is it the degradation products? Trends Mol. Med. 2012, 18, 138-144. [CrossRef]

23. Wang, Y.-J.; Pan, M.-H.; Cheng, A.-L.; Lin, L.-I.; Ho, Y.-S.; Hsieh, C.-Y.; Lin, J.-K. Stability of curcumin in buffer solutions and characterization of its degradation products. J. Pharm. Biomed. Anal. 1997, 15, 1867-1876. [CrossRef]

24. Schneider, C.; Gordon, O.N.; Edwards, R.L.; Luis, P.B. Degradation of Curcumin: From Mechanism to Biological Implications. J. Agric. Food Chem. 2015, 63, 7606-7614. [CrossRef] [PubMed]

25. Griesser, M.; Pistis, V.; Suzuki, T.; Tejera, N.; Pratt, D.A.; Schneider, C. Autoxidative and cyclooxygenase-2 catalyzed transformation of the dietary chemopreventive agent curcumin. J. Biol. Chem. 2011, 286, 1114-1124. [CrossRef] [PubMed]

26. Aggarwal, B.B.; Sundaram, C.; Malani, N.; Haruyo, I. Curcumin: The Indian solid gold. In The Molecular Targets and Therapeutics Uses of Curcumin in Health and Disease; Aggarwal, B.B., Surh, Y.-J., Shishodia, S., Eds.; Springer Science: Boston MA, USA, 2007; Volume 595, pp. 1-75.

27. Reinke, A.A.; Gestwicki, J.E. Structure-activity relationships of amyloid beta-aggregation inhibitors based on curcumin: Influence of linker length and flexibility. Chem. Biol. Drug Des. 2007, 70, 206-215. [CrossRef] [PubMed]

28. Ray, B.; Lahiri, D.K. Neuroinflammation in Alzheimer's disease: Different molecular targets and potential therapeutic agents including curcumin. Curr. Opin. Pharmacol. 2009, 9, 434-444. [CrossRef] [PubMed]

29. Kasi, P.D.; Tamilselvam, R.; Skalicka-Woźniak, K.; Nabavi, S.F.; Daglia, M.; Bishayee, A.; Pazoki-Toroudi, H.; Nabavi, S.M. Molecular targets of curcumin for cancer therapy: An updated review. Tumor Biol. 2016, 37, 13017-13028. [CrossRef] [PubMed]

30. Zhou, H.; Beevers, C.S.; Huang, S. The targets of curcumin. Curr. Drug Targets 2011, 12, 332-347. [CrossRef]

31. Aguzzi, A.; O'Connor, T. Protein aggregation diseases: Pathogenicity and therapeutic perspectives. Nat. Rev. Drug Discov. 2010, 9, 237-248. [CrossRef]

32. Hafner-Bratkovič, I.; Gašperšič, J.; Šmid, L.M.; Bresjanac, M.; Jerala, R. Curcumin binds to the $\alpha$-helical intermediate and to the amyloid form of prion protein -A new mechanism for the inhibition of PrPSc accumulation. J. Neurochem. 2008, 104, 1553-1564. [CrossRef]

33. Caughey, B.; Raymond, L.D.; Raymond, G.J.; Maxson, L.; Silveira, J.; Baron, G.S. Inhibition of protease-resistant prion protein accumulation in vitro by curcumin. J. Virol. 2003, 77, 5499-5502. [CrossRef]

34. Pandey, N.; Strider, J.; Nolan, W.C.; Yan, S.X.; Galvin, J.E. Curcumin inhibits aggregation of $\alpha$-synuclein. Acta Neuropathol. 2008, 115, 479-489. [CrossRef]

35. Brahmkhatri, V.; Sharma, N.; Punnepalli, S.; D'Souza, A.; Raghothama, S.; Atreya, H.S. Curcumin nanoconjugate Inhibits aggregation of $\mathrm{N}$-terminal region $(\mathrm{A} \beta-16)$ of an amyloid beta peptide. New J. Chem. 2018, 42, 19881-19892. [CrossRef]

36. Mithu, V.S.; Sarkar, B.; Bhowmik, D.; Das, A.K.; Chandrakesan, M. Curcumin Alters the Salt Bridge-containing Turn Region in amyloid $\beta(1-42)$ aggregates. J. Biol. Chem. 2014, 289, 11122-11131. [CrossRef] [PubMed]

37. Yang, F.; Lim, G.P.; Begum, A.N.; Ubeda, O.J.; Simmons, M.R.; Ambegaokar, S.S.; Chen, P.; Kayed, R.; Glabe, C.G.; Frautschy, S.A.; et al. Curcumin Inhibits Formation of Amyloid $\beta$ Oligomers and Fibrils, Binds Plaques, and Reduces Amyloid in vivo. J. Biol. Chem. 2005, 280, 5892-5901. [CrossRef] [PubMed]

38. Huang, X.; Atwood, Æ.C.S.; Moir, Æ.R.D.; Hartshorn, M.A.; Tanzi, Æ.R.E.; Bush, A.I. Trace metal contamination initiates the apparent auto-aggregation, amyloidosis, and oligomerization of Alzheimer's A $\beta$ peptides. J. Biol. Inorg. Chem. 2004, 9, 954-960. [CrossRef] [PubMed]

39. Cole, G.M.; Teter, B.; Frautschy, S.A. Neuropretective effects of curcumin. In The Molecular Targets and Therapeutic Uses of Curcumin in Health and Disease; Aggarwal, B.B., Surh, Y.J., Shishodia, S., Eds.; Springer: Boston, MA, USA, 2007; Volume 595, pp. 197-212. 
40. Vassar, R. Bace 1 The $\beta$-secretase enzyme in alzheimer's disease. J. Mol. Neurosci. 2004, 23, $105-113$. [CrossRef]

41. DiSabato, D.J.; Quan, N.; Godbout, J.P. Neuroinflammation: The Devil is in the Details. J. Neurochem. 2016, 139, 136-153. [CrossRef] [PubMed]

42. Karlstetter, M.; Lippe, E.; Walczak, Y.; Moehle, C.; Aslanidis, A.; Mirza, M.; Langmann, T. Curcumin is a potent modulator of microglial gene expression and migration. J. Neuroinflammation 2011, 8, 1-12. [CrossRef]

43. Tizabi, Y.; Hurley, L.L.; Qualls, Z.; Akinfiresoye, L. Relevance of the anti-inflammatory properties of curcumin in neurodegenerative diseases and depression. Molecules 2014, 19, 20864-20879. [CrossRef]

44. Yin, H.; Guo, Q.; Li, X.; Tang, T.; Li, C.; Wang, H.; Sun, Y.; Feng, Q.; Ma, C.; Gao, C.; et al. Curcumin Suppresses IL-1 $\beta$ Secretion and Prevents Inflammation through Inhibition of the NLRP3 Inflammasome. J. Immunol. 2018, 200, 2835-2846. [CrossRef]

45. Jurrmann, N.; Brigelius-Flohe, R.; Bol, G.F. Curcumin blocks interleukin-1 (IL-1) signaling by inhibiting the recruitment of the IL-1 receptor-associated kinase IRAK in murine thymoma EL-4 cells. J. Nutr. 2005, 135, 1859-1864. [CrossRef]

46. Devi, Y.S.; DeVine, M.; DeKuiper, J.; Ferguson, S.; Fazleabas, A.T. Inhibition of IL-6 signaling pathway by curcumin in uterine decidual cells. PLoS ONE 2015, 10, e0125627. [CrossRef] [PubMed]

47. Sahebkar, A.; Cicero, A.F.G.; Simental-Mendía, L.E.; Aggarwal, B.B.; Gupta, S.C. Curcumin downregulates human tumor necrosis factor- $\alpha$ levels: A systematic review and meta-analysis ofrandomized controlled trials. Pharmacol. Res. 2016, 107, 234-242. [CrossRef] [PubMed]

48. Singh, S.; Aggarwal, B.B. Activation of transcription factor NF-K B is suppressed by curcumin (diferuloylmethane). J. Biol. Chem. 1995, 270, 24995-25000. [CrossRef] [PubMed]

49. Aggarwal, B.B.; Gupta, S.C.; Sung, B. Curcumin: An orally bioavailable blocker of TNF and other pro-inflammatory biomarkers. Br. J. Pharmacol. 2013, 169, 1672-1692. [PubMed]

50. Howe, C.L.; LaFrance-Corey, R.G.; Goddery, E.N.; Johnson, R.K.; Mirchia, K. Neuronal CCL2 expression drives inflammatory monocyte infiltration into the brain during acute virus infection. J. Neuroinflamm. 2017, 14, 1-14. [CrossRef] [PubMed]

51. Zhang, Z.-J.; Zhao, L.-X.; Cao, D.-L.; Zhang, X.; Gao, Y.-J.; Xia, C. Curcumin Inhibits LPS-Induced CCL2 Expression via JNK Pathway in C6 Rat Astrocytoma Cells. Cell. Mol. Neurobiol. 2012, 32, 1003-1010. [CrossRef] [PubMed]

52. Herman, J.G.; Stadelman, H.L.; Roselli, C.E. Curcumin blocks CCL2-induced adhesion, motility and invasion, in part, through down-regulation of CCL2 expression and proteolytic activity. Int. J. Oncol. 2009, 34, 1319-1327. [PubMed]

53. Midura-Kiela, M.T.; Radhakrishnan, V.; Kiela, P. Curcumin inhibits interferon- $\gamma$ signaling in colonic epithelial cells. Am. J. Physiol. Liver Phisiol. 2012, 302, G86-G96. [CrossRef] [PubMed]

54. Ogadimma, I.; Uzairu, A.; Eyije, S.; Ola, S. Evaluation of the antioxidant properties of curcumin derivatives by genetic function algorithm. J. Adv. Res. 2018, 12, 47-54.

55. Bendary, E.; Francis, R.R.; Ali, H.M.G.; Sarwat, M.I.; Hady, S. El Antioxidant and structure-Activity relationships (SARs) of some phenolic and anilines compounds. Ann. Agric. Sci. 2013, 58, 173-181.

56. Menon, V.P.; Sudheer, A.R. Antioxidant and anti-inflamatory properties of curcumin. In The Molecular Targets and Therapeutic Uses of Curcumin in Health and Disease; Aggarwal, B.B., Surh, Y.-J., Shishodia, S., Eds.; Springer International Publishing: Cham, Switzerland, 2007; pp. 105-126.

57. Chen, Y.; Xiao, H.; Zheng, J.; Liang, G. Structure-Thermodynamics-Antioxidant Activity Relationships of Selected Natural Phenolic Acids and Derivatives: An Experimental and Theoretical Evaluation. PLoS ONE 2015, 10, e0121276. [CrossRef] [PubMed]

58. Zbarsky, V.; Datla, K.P.; Parkar, S.; Rai, D.K.; Okezie, I.; Dexter, D.T. Neuroprotective properties of the natural phenolic antioxidants curcumin and naringenin but not quercetin and fisetin in a 6-OHDA model of Parkinson's disease. Free Radic. Res. 2009, 39, 1119-1125. [CrossRef]

59. Maiti, P.; Dunbar, G.L. Use of curcumin, a natural polyphenol for targeting molecular pathways in treating age-related neurodegenerative diseases. Int. J. Mol. Sci. 2018, 19, 1637. [CrossRef]

60. Barzegar, A.; Moosavi-movahedi, A.A. Intracellular ROS Protection Efficiency and Free Radical- Scavenging Activity of Curcumin. PLoS ONE 2011, 6, e26012. [CrossRef] 
61. González-Reyes, S.; Guzmán-Beltrán, S.; Medina-Campos, O.N.; Pedraza-Chaverri, J. Curcumin Pretreatment Induces Nrf2 and an Antioxidant Response and Prevents Hemin-Induced Toxicity in Primary Cultures of Cerebellar Granule Neurons of Rats. Oxid. Med. Cell. Longev. 2013, 2013, 1-14. [CrossRef] [PubMed]

62. Haryuna, T.; Munir, D.; Maria, A.; Bashiruddin, J. The Antioxidant Effect of Curcumin on Cochlear Fibroblasts in Rat Models of Diabetes Mellitus. Iran J. Otorhinolaryngol. 2017, 29, 197-202. [PubMed]

63. Wahlang, B.; Pawar, Y.B.; Bansal, A.K. Identification of permeability-related hurdles in oral delivery of curcumin using the Caco-2 cell model. Eur. J. Pharm. Biopharm. 2011, 77, 275-282. [CrossRef]

64. Holder, G.M.; Plummer, J.L.; Ryan, A.J. The metabolism and excretion of curcumin (1,7-bis-(4-hydroxy-3-methoxyphenyl)-1,6-heptadiene-3,5-dione) in the rat. Xenobiotica 1978, 8, 761-768. [CrossRef]

65. Sharma, R.A. Phase I Clinical Trial of Oral Curcumin: Biomarkers of Systemic Activity and Compliance. Clin. Cancer Res. 2004, 10, 6847-6854. [CrossRef]

66. Gangurde, A.B.; Kundaikar, H.S.; Javeer, S.D.; Jaiswar, D.R.; Degani, M.S.; Amin, P.D. Enhanced solubility and dissolution of curcumin by a hydrophilic polymer solid dispersion and its in silico molecular modeling studies. J. Drug Deliv. Sci. Technol. 2015, 29, 226-237. [CrossRef]

67. Chuah, A.M.; Jacob, B.; Jie, Z.; Ramesh, S.; Mandal, S.; Puthan, J.K.; Deshpande, P.; Vaidyanathan, V.V.; Gelling, R.W.; Patel, G.; et al. Enhanced bioavailability and bioefficacy of an amorphous solid dispersion of curcumin. Food Chem. 2014, 156, 227-233. [CrossRef] [PubMed]

68. Wang, Y.; Wang, C.; Zhao, J.; Ding, Y.; Li, L. Journal of Colloid and Interface Science A cost-effective method to prepare curcumin nanosuspensions with enhanced oral bioavailability. J. Colloid Interface Sci. 2017, 485, 91-98. [CrossRef] [PubMed]

69. Li, X.; Yuan, H.; Zhang, C.; Chen, W.; Cheng, W.; Chen, X.; Ye, X. Preparation and in-vitro/in-vivo evaluation of curcumin nanosuspension with solubility enhancement. J. Pharm. Pharmacol. 2016, 68, 980-988. [CrossRef] [PubMed]

70. Dokania, S.; Joshi, A.K. Self-microemulsifying drug delivery system (SMEDDS)—Challenges and road ahead. Drug Deliv. 2015, 22, 675-690. [CrossRef] [PubMed]

71. Wu, X.; Xu, J.; Huang, X.; Wen, C. Self-microemulsifying drug delivery system improves curcumin dissolution and bioavailability. Drug Dev. Ind. Pharm. 2011, 37, 15-23. [CrossRef] [PubMed]

72. Jaisamut, P.; Wiwattanawongsa, K.; Graidist, P.; Sangsen, Y.; Wiwattanapatapee, R. Enhanced Oral Bioavailability of Curcumin Using a Supersaturatable Self-Microemulsifying System Incorporating a Hydrophilic Polymer; In Vitro and In Vivo Investigations. AAPS PharmSciTech 2018, 19, 730-740. [CrossRef]

73. Bele, M.H.; Shaikh, A.A.; Paralkar, S.G. To enhance the solubility of curcumin by solid self-microemulsifying drug delivery system (SMEDDS). Indo Am. J. Pharm. Res. 2017, 7, 8587-8607.

74. Cui, J.; Yu, B.; Zhao, Y.; Zhu, W.; Li, H.; Lou, H.; Zhai, G. Enhancement of oral absorption of curcumin by self-microemulsifying drug delivery systems. Int. J. Pharm. 2009, 371, 148-155. [CrossRef]

75. Yallapu, M.M.; Jaggi, M.; Chauhan, S.C. Curcumin nanoformulations: A future nanomedicine for cancer. Drug Discov. Today 2012, 17, 71-80. [CrossRef]

76. Sun, M.; Su, X.; Ding, B.; He, X.; Liu, X.; Yu, A.; Lou, H.; Zhai, G. Advances in nanotechnology-based delivery systems for curcumin. Nanomedicine 2012, 7, 1085-1100. [CrossRef]

77. Kreuter, J. Nanoparticles-a historical perspective. Int. J. Pharm. 2007, 331, 1-10. [CrossRef] [PubMed]

78. Leson, A. There is plenty of room at the bottom. Vak. Forsch. und Prax. 2005, 17, 123. [CrossRef]

79. Khanna, S.C.; Soliva, M.; Speiser, P. Epoxy resin beads as a pharmaceutical dosage form II: Dissolution studies of epoxy-amine beads and release of drug. J. Pharm. Sci. 1969, 58, 1385-1388. [CrossRef] [PubMed]

80. Kreuter, J.; Alyautdin, R.N.; Kharkevich, D.A.; Ivanov, A.A. Passage of peptides through the blood-brain barrier with colloidal polymer particles (nanoparticles). Brain Res. 1995, 674, 171-174. [CrossRef]

81. Müller, R.H.; Maaßen, S.; Weyhers, H.; Mehnert, W. Phagocytic uptake and cytotoxicity of solid lipid nanoparticles (SLN) sterically stabilized with poloxamine 908 and poloxamer 407. J. Drug Target. 1996, 4, 161-170. [CrossRef] [PubMed]

82. Xu, Y.; Kim, C.S.; Saylor, D.M.; Koo, D. Polymer degradation and drug delivery in PLGA-based drug-polymer applications: A review of experiments and theories. J. Biomed. Mater. Res. Part B Appl. Biomater. 2017, 105, 1692-1716. [CrossRef] [PubMed]

83. Barenholz, Y. Doxil-The first FDA-approved nano-drug: Lessons learned. J. Control. Release 2012, 160, 117-134. [CrossRef] 
84. Jansook, P.; Ogawa, N.; Loftsson, T. Cyclodextrins: Structure, physicochemical properties and pharmaceutical applications. Int. J. Pharm. 2018, 535, 272-284. [CrossRef]

85. He, X.; Zhu, Y.; Wang, M.; Jing, G.; Zhu, R.; Wang, S. Antidepressant effects of curcumin and HU-211 coencapsulated solid lipid nanoparticles against corticosterone-induced cellular and animal models of major depression. Int. J. Nanomed. 2016, 11, 4975-4990. [CrossRef]

86. Kakkar, V.; Muppu, S.K.; Chopra, K.; Kaur, I.P. Curcumin loaded solid lipid nanoparticles: An efficient formulation approach for cerebral ischemic reperfusion injury in rats. Eur. J. Pharm. Biopharm. 2013, 85, 339-345. [CrossRef]

87. Sandhir, R.; Yadav, A.; Mehrotra, A.; Sunkaria, A.; Singh, A.; Sharma, S. Curcumin nanoparticles attenuate neurochemical and neurobehavioral deficits in experimental model of Huntington's disease. Neuromol. Med. 2014, 16, 106-118. [CrossRef] [PubMed]

88. Kundu, P.; Das, M.; Tripathy, K.; Sahoo, S.K. Delivery of Dual Drug Loaded Lipid Based Nanoparticles across the Blood-Brain Barrier Impart Enhanced Neuroprotection in a Rotenone Induced Mouse Model of Parkinson's Disease. ACS Chem. Neurosci. 2016, 7, 1658-1670. [CrossRef] [PubMed]

89. Ramalingam, P.; Ko, Y.T. Enhanced oral delivery of curcumin from N-trimethyl chitosan surface-modified solid lipid nanoparticles: Pharmacokinetic and brain distribution evaluations. Pharm. Res. 2015, 32, 389-402. [CrossRef] [PubMed]

90. Kakkar, V.; Kaur, I.P. Evaluating potential of curcumin loaded solid lipid nanoparticles in aluminium induced behavioural, biochemical and histopathological alterations in mice brain. Food Chem. Toxicol. 2011, 49, 2906-2913. [CrossRef] [PubMed]

91. Sadegh, M.S.; Azadi, A.; Izadi, Z.; Kurd, M.; Dara, T.; Dibaei, M.; Sharif Zadeh, M.; Akbari Javar, H.; Hamidi, M. Brain Delivery of Curcumin Using Solid Lipid Nanoparticles and Nanostructured Lipid Carriers: Preparation, Optimization, and Pharmacokinetic Evaluation. ACS Chem. Neurosci. 2018, 10, 728-739. [CrossRef] [PubMed]

92. Madane, R.G.; Mahajan, H.S. Curcumin-loaded nanostructured lipid carriers (NLCs) for nasal administration: Design, characterization, and in vivo study. Drug Deliv. 2016, 23, 1326-1334. [PubMed]

93. Fang, M.; Jin, Y.; Bao, W.; Gao, H.; Xu, M.; Wang, D.; Wang, X.; Yao, P.; Liu, L. In vitro characterization and in vivo evaluation of nanostructured lipid curcumin carriers for intragastric administration. Int. J. Nanomed. 2012, 7, 5395-5404. [CrossRef]

94. Meng, F.; Asghar, S.; Gao, S.; Su, Z.; Song, J.; Huo, M.; Meng, W.; Ping, Q.; Xiao, Y. A novel LDL-mimic nanocarrier for the targeted delivery of curcumin into the brain to treat Alzheimer's disease. Colloids Surfaces $B$ Biointerfaces 2015, 134, 88-97. [CrossRef]

95. Meng, F.; Asghar, S.; Xu, Y.; Wang, J.; Jin, X.; Wang, Z.; Wang, J.; Ping, Q.; Zhou, J.; Xiao, Y. Design and evaluation of lipoprotein resembling curcumin-encapsulated protein-free nanostructured lipid carrier for brain targeting. Int. J. Pharm. 2016, 506, 46-56. [CrossRef]

96. Ameruoso, A.; Palomba, R.; Palange, A.L.; Cervadoro, A.; Lee, A.; Di Mascolo, D.; Decuzzi, P. Ameliorating amyloid- $\beta$ fibrils triggered inflammation via curcumin-loaded polymeric nanoconstructs. Front. Immunol. 2017, 8, 1411. [CrossRef]

97. Mulik, R.S.; Mönkkönen, J.; Juvonen, R.O.; Mahadik, K.R.; Paradkar, A.R. ApoE3 Mediated Poly(butyl) Cyanoacrylate Nanoparticles Containing Curcumin: Study of Enhanced Activity of Curcumin against Beta Amyloid Induced Cytotoxicity Using In Vitro Cell Culture Model. Mol. Pharm. 2010, 7, 815-825. [CrossRef] [PubMed]

98. Mulik, R.S.; Mönkkönen, J.; Juvonen, R.O.; Mahadik, K.R.; Paradkar, A.R. ApoE3 mediated polymeric nanoparticles containing curcumin: Apoptosis induced in vitro anticancer activity against neuroblastoma cells. Int. J. Pharm. 2012, 437, 29-41. [CrossRef]

99. Szymusiak, M.; Hu, X.; Leon Plata, P.A.; Ciupinski, P.; Wang, Z.J.; Liu, Y. Bioavailability of curcumin and curcumin glucuronide in the central nervous system of mice after oral delivery of nano-curcumin. Int. J. Pharm. 2016, 511, 415-423. [CrossRef]

100. Tsai, Y.M.; Chien, C.F.; Lin, L.C.; Tsai, T.H. Curcumin and its nano-formulation: The kinetics of tissue distribution and blood-brain barrier penetration. Int. J. Pharm. 2011, 416, 331-338. [CrossRef] [PubMed]

101. Hu, X.; Huang, F.; Szymusiak, M.; Liu, Y.; Wang, Z.J. Curcumin Attenuates Opioid Tolerance and Dependence by Inhibiting $\mathrm{Ca}^{2+} /$ Calmodulin-Dependent Protein Kinase II $\alpha$ Activity. J. Pharmacol. Exp. Ther. 2015, 352, 420-428. [CrossRef] [PubMed] 
102. Yadav, A.; Lomash, V.; Samim, M.; Flora, S.J.S. Curcumin encapsulated in chitosan nanoparticles: A novel strategy for the treatment of arsenic toxicity. Chem. Biol. Interact. 2012, 199, 49-61. [CrossRef] [PubMed]

103. Hashemian, M.; Anisian, D.; Ghasemi-Kasman, M.; Akbari, A.; Khalili-Fomeshi, M.; Ghasemi, S.; Ahmadi, F.; Moghadamnia, A.A.; Ebrahimpour, A. Curcumin-loaded chitosan-alginate-STPP nanoparticles ameliorate memory deficits and reduce glial activation in pentylenetetrazol-induced kindling model of epilepsy. Prog. Neuro-Psychopharmacol. Biol. Psychiatry 2017, 79, 462-471. [CrossRef]

104. Yang, R.; Zheng, Y.; Wang, Q.; Zhao, L. Curcumin-loaded chitosan-bovine serum albumin nanoparticles potentially enhanced $\mathrm{A} \beta 42$ phagocytosis and modulated macrophage polarization in Alzheimer's disease. Nanoscale Res. Lett. 2018, 13, 1-9. [CrossRef]

105. Tiwari, S.K.; Agarwal, S.; Seth, B.; Yadav, A.; Nair, S.; Bhatnagar, P.; Karmakar, M.; Kumari, M.; Chauhan, L.K.S.; Patel, D.K.; et al. Curcumin-loaded nanoparticles potently induce adult neurogenesis and reverse cognitive deficits in Alzheimer's disease model via canonical Wnt/ $\beta$-catenin pathway. ACS Nano 2014, 8, 76-103. [CrossRef]

106. Pieretti, S.; Ranjan, A.P.; Di Giannuario, A.; Mukerjee, A.; Marzoli, F.; Di Giovannandrea, R.; Vishwanatha, J.K. Curcumin-loaded Poly (D, L-lactide-co-glycolide) nanovesicles induce antinociceptive effects and reduce pronociceptive cytokine and BDNF release in spinal cord after acute administration in mice. Colloids Surf. B Biointerfaces 2017, 158, 379-386. [CrossRef]

107. Mathew, A.; Fukuda, T.; Nagaoka, Y.; Hasumura, T.; Morimoto, H.; Yoshida, Y.; Maekawa, T.; Venugopal, K.; Kumar, D.S. Curcumin loaded-PLGA nanoparticles conjugated with Tet-1 peptide for potential use in Alzheimer's disease. PLoS ONE 2012, 7, e32616. [CrossRef] [PubMed]

108. Fan, S.; Zheng, Y.; Liu, X.; Fang, W.; Chen, X.; Liao, W.; Jing, X.; Lei, M.; Tao, E.; Ma, Q.; et al. Curcumin-loaded PLGA-PEG nanoparticles conjugated with B6 peptide for potential use in Alzheimer's disease. Drug Deliv. 2018, 25, 1091-1102. [CrossRef] [PubMed]

109. Zhang, X.; Li, X.; Hua, H.; Wang, A.; Liu, W.; Li, Y.; Fu, F.; Shi, Y.; Sun, K. Cyclic hexapeptide-conjugated nanoparticles enhance curcumin delivery to glioma tumor cells and tissue. Int. J. Nanomed. 2017, 12, 5717-5732. [CrossRef] [PubMed]

110. Cui, Y.; Zhang, M.; Zeng, F.; Jin, H.; Xu, Q.; Huang, Y. Dual-Targeting Magnetic PLGA Nanoparticles for Codelivery of Paclitaxel and Curcumin for Brain Tumor Therapy. ACS Appl. Mater. Interfaces 2016, 8, 32159-32169. [CrossRef] [PubMed]

111. Orunoğlu, M.; Kaffashi, A.; Pehlivan, S.B.; Şahin, S.; Söylemezoğlu, F.; Karlı-Oğuz, K.; Mut, M. Effects of curcumin-loaded PLGA nanoparticles on the RG2 rat glioma model. Mater. Sci. Eng. C 2017, 78, 32-38. [CrossRef] [PubMed]

112. Zhang, Z.Y.; Jiang, M.; Fang, J.; Yang, M.F.; Zhang, S.; Yin, Y.X.; Li, D.W.; Mao, L.L.; Fu, X.Y.; Hou, Y.; et al. Enhanced Therapeutic Potential of Nano-Curcumin Against Subarachnoid Hemorrhage-Induced Blood-Brain Barrier Disruption Through Inhibition of Inflammatory Response and Oxidative Stress. Mol. Neurobiol. 2017, 54, 1-14. [CrossRef] [PubMed]

113. Cheng, K.K.; Yeung, C.F.; Ho, S.W.; Chow, S.F.; Chow, A.H.L.; Baum, L. Highly Stabilized Curcumin Nanoparticles Tested in an In Vitro Blood-Brain Barrier Model and in Alzheimer's Disease Tg2576 Mice. AAPS J. 2013, 15, 324-336. [CrossRef]

114. Yang, L.; Gao, S.; Asghar, S.; Liu, G.; Song, J.; Wang, X.; Ping, Q.; Zhang, C.; Xiao, Y. Hyaluronic acid/chitosan nanoparticles for delivery of curcuminoid and its in vitro evaluation in glioma cells. Int. J. Biol. Macromol. 2015, 72, 1391-1401. [CrossRef]

115. Mirgani, M.T.; Isacchi, B.; Sadeghizadeh, M.; Marra, F.; Bilia, A.R.; Mowla, S.J.; Najafi, F.; Babaei, E. Dendrosomal curcumin nanoformulation downregulates pluripotency genes via miR-145 activation in U87MG glioblastoma cells. Int. J. Nanomed. 2014, 9, 403-417.

116. Kumar, A.; Ahuja, A.; Ali, J.; Baboota, S. Curcumin-loaded lipid nanocarrier for improving bioavailability, stability and cytotoxicity against malignant glioma cells. Drug Deliv. 2016, 23, 214-229. [CrossRef]

117. Nasr, M. Development of an optimized hyaluronic acid-based lipidic nanoemulsion co-encapsulating two polyphenols for nose to brain delivery. Drug Deliv. 2016, 23, 1444-1452. [CrossRef] [PubMed]

118. Vaz, G.R.; Hädrich, G.; Bidone, J.; Rodrigues, J.L.; Falkembach, M.C.; Putaux, J.L.; Hort, M.A.; Monserrat, J.M.; Varela Junior, A.S.; Teixeira, H.F.; et al. Development of Nasal Lipid Nanocarriers Containing Curcumin for Brain Targeting. J. Alzheimer's Dis. 2017, 59, 961-974. [CrossRef] [PubMed] 
119. Singh, A.K.; Jiang, Y.; Gupta, S.; Younus, M.; Ramzan, M. Anti-Inflammatory Potency of Nano-Formulated Puerarin and Curcumin in Rats Subjected to the Lipopolysaccharide-Induced Inflammation. J. Med. Food 2013, 16, 899-911. [CrossRef] [PubMed]

120. Cheng, K.K.; Chan, P.S.; Fan, S.; Kwan, S.M.; Yeung, K.L.; Wáng, Y.X.J.; Chow, A.H.L.; Wu, E.X.; Baum, L. Curcumin-conjugated magnetic nanoparticles for detecting amyloid plaques in Alzheimer's disease mice using magnetic resonance imaging (MRI). Biomaterials 2015, 44, 155-172. [CrossRef] [PubMed]

121. Ghorbani, M.; Bigdeli, B.; Jalili-baleh, L.; Baharifar, H.; Akrami, M.; Dehghani, S.; Goliaei, B.; Amani, A.; Lotfabadi, A.; Rashedi, H.; et al. Curcumin-lipoic acid conjugate as a promising anticancer agent on the surface of gold-iron oxide nanocomposites: A pH-sensitive targeted drug delivery system for brain cancer theranostics. Eur. J. Pharm. Sci. 2018, 114, 175-188. [CrossRef] [PubMed]

122. Naserzadeh, P.; Hafez, A.A.; Abdorahim, M.; Abdollahifar, M.A.; Shabani, R.; Peirovi, H.; Simchi, A.; Ashtari, K. Curcumin loading potentiates the neuroprotective efficacy of $\mathrm{Fe}_{3} \mathrm{O}_{4}$ magnetic nanoparticles in cerebellum cells of schizophrenic rats. Biomed. Pharmacother. 2018, 108, 1244-1252. [CrossRef] [PubMed]

123. Fang, J.H.; Chiu, T.L.; Huang, W.C.; Lai, Y.H.; Hu, S.H.; Chen, Y.Y.; Chen, S.Y. Dual-Targeting Lactoferrin-Conjugated Polymerized Magnetic Polydiacetylene-Assembled Nanocarriers with Self-Responsive Fluorescence/Magnetic Resonance Imaging for in vivo Brain Tumor Therapy. Adv. Healthc. Mater. 2016, 5, 688-695. [CrossRef]

124. Lazar, A.N.; Mourtas, S.; Youssef, I.; Parizot, C.; Dauphin, A.; Delatour, B.; Antimisiaris, S.G.; Duyckaerts, C. Curcumin-conjugated nanoliposomes with high affinity for A $\beta$ deposits: Possible applications to Alzheimer disease. Nanomed. Nanotechnol. Biol. Med. 2013, 9, 712-721. [CrossRef]

125. Li, W.; Zhou, M.; Xu, N.; Hu, Y.; Wang, C.; Li, D.; Liu, L.; Li, D. Comparative analysis of protective effects of curcumin, curcumin- $\beta$-cyclodextrin nanoparticle and nanoliposomal curcumin on unsymmetrical dimethyl hydrazine poisoning in mice. Bioengineered 2016, 7, 334-341. [CrossRef]

126. Citron, M. Alzheimer's disease: Strategies for disease modification. Nat. Rev. Drug Discov. 2010, 9, 387-398. [CrossRef]

127. Ballatore, C.; Lee, V.M.-Y.; Trojanowski, J.Q. Tau-mediated neurodegeneration in Alzheimer's disease and related disorders. Nat. Rev. Neurosci. 2007, 8, 663-672. [CrossRef] [PubMed]

128. Djiokeng Paka, G.; Doggui, S.; Zaghmi, A.; Safar, R.; Dao, L.; Reisch, A.; Klymchenko, A.; Roullin, V.G.; Joubert, O.; Ramassamy, C. Neuronal Uptake and Neuroprotective Properties of Curcumin-Loaded Nanoparticles on SK-N-SH Cell Line: Role of Poly(lactide-co-glycolide) Polymeric Matrix Composition. Mol. Pharm. 2016, 13, 391-403. [CrossRef] [PubMed]

129. Barbara, R.; Belletti, D.; Pederzoli, F.; Masoni, M.; Keller, J.; Ballestrazzi, A.; Vandelli, M.A.; Tosi, G.; Grabrucker, A.M. Novel Curcumin loaded nanoparticles engineered for Blood-Brain Barrier crossing and able to disrupt A $\beta$ aggregates. Int. J. Pharm. 2017, 526, 413-424. [CrossRef] [PubMed]

130. Huang, N.; Lu, S.; Liu, X.-G.; Zhu, J.; Wang, Y.-J.; Liu, R.-T. PLGA nanoparticles modified with a BBB-penetrating peptide co-delivering $\mathrm{A} \beta$ generation inhibitor and curcumin attenuate memory deficits and neuropathology in Alzheimer's disease mice. Oncotarget 2017, 8, 81001-81013. [PubMed]

131. Siddique, Y.H.; Khan, W.; Singh, B.R.; Naqvi, A.H. Synthesis of Alginate-Curcumin Nanocomposite and Its Protective Role in Transgenic Drosophila Model of Parkinson's Disease. ISRN Pharmacol. 2013, 2013, 794582. [CrossRef] [PubMed]

132. Bollimpelli, V.S.; Kumar, P.; Kumari, S.; Kondapi, A.K. Neuroprotective effect of curcumin-loaded lactoferrin nano particles against rotenone induced neurotoxicity. Neurochem. Int. 2016, 95, 37-45. [CrossRef] [PubMed]

133. Zhang, N.; Yan, F.; Liang, X.; Wu, M.; Shen, Y.; Chen, M.; Xu, Y.; Zou, G.; Jiang, P.; Tang, C.; et al. Localized delivery of curcumin into brain with polysorbate 80 -modified cerasomes by ultrasound-targeted microbubble destruction for improved Parkinson's disease therapy. Theranostics 2018, 8, 2264-2277. [CrossRef] [PubMed]

(C) 2019 by the authors. Licensee MDPI, Basel, Switzerland. This article is an open access article distributed under the terms and conditions of the Creative Commons Attribution (CC BY) license (http://creativecommons.org/licenses/by/4.0/). 